\title{
Spatial and Temporal Evolution Characteristics and Sustainability Analysis of Groundwater in a Typical Inland River Oasis Irrigation Area
}

Chenyu Guo ( $\sim$ guochenyu16@mails.ucas.ac.cn )

Xinjiang Institute of Ecology and Geography https://orcid.org/0000-0003-2561-3367

Tie Liu

Xinjiang Institute of Ecology and Geography

\section{Yue Huang}

Xinjiang Institute of Ecology and Geography

\section{Yaxuan Niu}

Xinjiang Institute of Ecology and Geography

\section{Zhengyang Li}

Xinjiang Institute of Ecology and Geography

\section{Zheng Wang}

Xinjiang Institute of Ecology and Geography

Chanjuan Zan

Xinjiang Institute of Ecology and Geography

\section{Shamshodbek Akmalov}

Tashkent institute of irrigation and agricultural mechanization engineers

\section{Yongchao Duan}

Wuxin University

\section{Feng Guo}

China national cotton research and development center

\section{Research Article}

Keywords: Arid irrigated areas, Groundwater, Trend analysis, Attribution analysis, Ecological water level, Groundwater management

Posted Date: January 17th, 2022

DOI: https://doi.org/10.21203/rs.3.rs-1053390/v1

License: (c) (i) This work is licensed under a Creative Commons Attribution 4.0 International License. 



\section{Spatial and temporal evolution characteristics and sustainability analysis of groundwater in a typical inland river oasis irrigation area}

Chenyu Guo ${ }^{1,2,3}$, Tie Liu ${ }^{1,2,4, *}$, Yue Huang ${ }^{1,2,4}$, Yaxuan Niu ${ }^{1,2,3}$, Zhengyang Li $^{1,2,3}$,

Zheng Wang ${ }^{1,2,3}$, Chanjuan Zan ${ }^{1,2,3}$, Shamshodbek Akmalov ${ }^{4,5}$, Yongchao Duan 1,2,3,6, Feng $\mathrm{Guo}^{7}$

\section{Affiliations}

1 State Key Laboratory of Desert and Oasis Ecology, Xinjiang Institute of Ecology and Geography, Chinese Academy of Sciences, Urumqi 830011, China

Chenyu Guo, Tie Liu, Yue Huang, Yaxuan Niu, Zhengyang Li, Zheng Wang, Chanjuan Zan, Yongchao Duan

2 Key Laboratory of GIS \& RS Application Xinjiang Uygur Autonomous Region, Urumqi 830011, China

Chenyu Guo, Tie Liu, Yue Huang, Yaxuan Niu, Zhengyang Li, Zheng Wang, Chanjuan Zan, Yongchao Duan

3 University of Chinese Academy of Sciences, Beijing 100049, China.

Chenyu Guo, Yaxuan Niu, Zhengyang Li, Zheng Wang, Chanjuan Zan, Yongchao Duan

4 CAS Research Center for Ecology and Environment of Central Asia, Urumqi 830011, China 
Tie Liu, Yue Huang, Shamshodbek Akmalov

5 Tashkent Institute of Irrigation and Agricultural Mechanization Engineers, Tashkent 999033, Uzbekistan.

Shamshodbek Akmalov

6 Wuxi University, Wuxi 214105, China.

Yongchao Duan

7 China National Cotton Research and Development Center, Urumqi 830091, China; guofeng501@163.com.

Feng Guo

Corresponding author: Tie Liu, E-mail: liutie@ms.xjb.ac.cn

\section{Key words}

Arid irrigated areas; Groundwater; Trend analysis; Attribution analysis;

Ecological water level; Groundwater management

\section{Highlights}

1. Under the scenario of increasing groundwater level volatility, the multiyear rate of change at various points in the region ranges from $-0.054 \mathrm{~m} / \mathrm{a}$ to $0.098 \mathrm{~m} / \mathrm{a}$, and the groundwater level in the entire area is rising at a rate of $0.015 \mathrm{~m} / \mathrm{a}$.

2. The ecological water level is defined between $1.78 \mathrm{~m}$ (salinization control limit) and $2.78 \mathrm{~m}$ (desertification control limit).

3. Since March, $72.2 \%$ of the regional groundwater level has exceeded the ecological water level by an average of $0.38 \mathrm{~m}$, and by July, $83.5 \%$ of the region has exceeded the 
ecological water level by an average of $0.98 \mathrm{~m}$, and the highest point is only $0.5 \mathrm{~m}$ from the ground. 


\section{Abstract}

The large amount of agricultural land development in the irrigation area of the lower Amudarya has led to a greater amount of water resources being introduced into the irrigation area. The high groundwater level in the irrigation area and the unreasonable management of water resources have led to the deterioration of the regional ecological environment. In the context of global climate change, we used a variety of trend analysis methods and correlation analysis methods and found that human activities are the main factors affecting regional annual groundwater level changes and annual groundwater level fluctuations, accounting for $67.6 \%$ and $78.9 \%$, respectively. These factors have led to a high temporal and spatial heterogeneity of the regional groundwater from 1990 to 2020: the multiyear rate of change at various points in the region ranges from $-0.054 \mathrm{~m} / \mathrm{a}$ to $0.098 \mathrm{~m} / \mathrm{a}$, and the groundwater level in the entire area is rising at a rate of $0.015 \mathrm{~m} / \mathrm{a}$. Under the scenario of increasing groundwater level volatility, the continuously rising water level requires us to consider whether this state will cause harm to the future area, so we used the capillary method to define the regional ecological water level as $1.78-2.78 \mathrm{~m}$. When exploring its relationship with regional groundwater, it was found that starting in March, $72.2 \%$ of the regional groundwater level exceeded the ecological water level by an average of $0.38 \mathrm{~m}$, and by July, $83.5 \%$ of the region exceeded the ecological water level by an average of $0.98 \mathrm{~m}$; furthermore, the highest point was only $0.5 \mathrm{~m}$ from the ground. Under the future changing trend of regional groundwater in the future, such results will cause a further deterioration of regional ecology, and sustainable groundwater exploitation methods 
with the goal of maintaining the ecological water level should urgently be proposed. 


\section{Graphical Abstract}

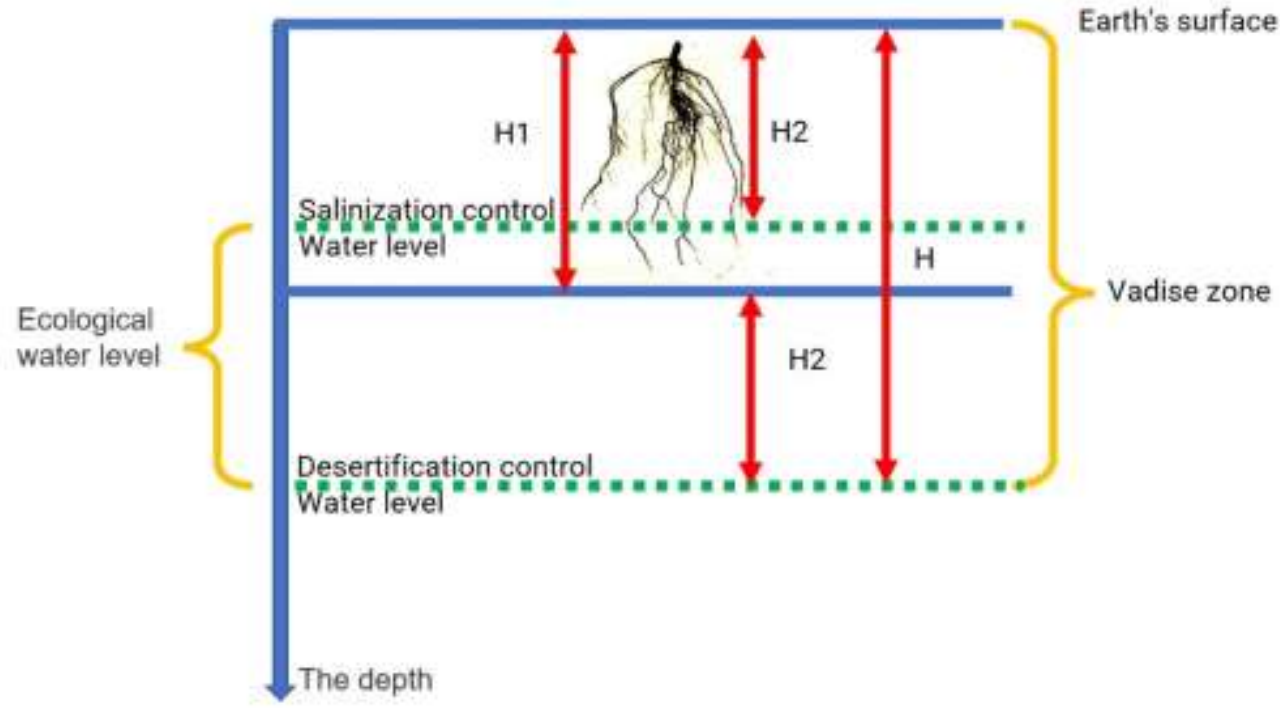




\section{Introduction}

Inland river basins are composed of mountain-oasis-desert-lake systems. Hydrology and ecology are sensitive to climate change and are severely affected by human activities. Therefore, water resources in inland river basins have strong temporal and spatial distribution characteristics. The Amudarya River is a typical inland river in the arid zone of Central Asia, with a total flow of $78.46 \mathrm{~km} 2 /$ year (Davis, 2012), and it spans most of Uzbekistan. Since 1960, with the construction of water conservancy facilities and irrigation system projects in the upper reaches of the Amudarya River, the middle and lower reaches of the Amudarya River have attracted a large number of immigrants who have reclaimed land for agricultural production, such as cotton and rice. By the 1990s, the Amudarya River was frequently experiencing dry-ups, and the interruption of the surface water supply caused the Aral Sea to shrink to approximately 6000 square kilometres, only one-tenth of the original lake surface (Izhitskiy et al., 2016; Micklin, 1988); thus, the Aral Sea crisis began. The water resources in the basin are becoming increasingly scarce, and ecological damage and environmental disasters are converging (Micklin, 2007). Since 2010, the area of the Aral Sea has been changing slowly. The reason is that it has reached a water balance that is mainly a result of evapotranspiration and groundwater recharge (Cretaux et al., 2005; Ruji et al., 2011). Groundwater from the irrigation area in the lower Amudarya River Delta, including Nukus, has become one of the most important sources of replenishment for the Aral Sea. Its changes are closely related to the changes in the area of the Aral Sea. Therefore, it provides insight into the spatiotemporal evolution of groundwater in the irrigation 
area. Analysing the main problems is also an important part of solving the Aral Sea problem.

Groundwater is an important part of the oasis water cycle (Famiglietti, 2014; Mi et al., 2016). A large amount of groundwater in arid irrigated areas is used to maintain the stability of agricultural activities, and groundwater has an important strategic position in the oasis economy and natural ecosystem security (Doell, 2009; Giordano, 2009; Siebert et al., 2010). For the Amudarya River irrigated area, with the substantial growth of the population, the water demand of crops has continuously increased, making the supply and management of regional irrigation water the main factor limiting crop production in the area (Cai et al., 2003; Ibragimov et al., 2007). According to statistics, approximately $90 \%$ of Uzbekistan's available water resources are used for irrigation every year. However, due to backwards irrigation methods and poor drainage systems, water management problems are further aggravated, and approximately $70 \%$ of water resources are wasted (Nezlin et al., 2004), which has led to a serious decline in groundwater quality (Giordano et al., 2010). Approximately 35-38\% of newly surveyed groundwater reservoirs are polluted to varying degrees. Shallow groundwater quality exceeding the standard, coupled with the wear and tear of the groundwater extraction system and the poor maintenance of wells, has caused the irrigation area to cease exploiting groundwater resources for irrigation, which has led to the continuous rise of groundwater levels in the irrigation area in recent years. Due to the high groundwater level, a large amount of groundwater is consumed through the process of ineffective evaporation under strong evaporation in arid areas (Kopec et al., 2013; Song 
et al., 2017), and this process causes the bottom soil salinity to rise and accumulate in the surface soil, thus increasing the degree of regional salinization. The secondary land degradation in some regions is serious (Jiang et al., 2020). Effective groundwater resource management and maintaining the sustainable development of regional groundwater are necessary. Accurately quantifying groundwater issues is a prerequisite for effective regional water resource management. However, current research on the groundwater level in the irrigation area of the Amudarya River basin is extremely rare. Only one study has described the macroscopic changes in the region (Pan et al., 2020), and there is a lack of groundwater research on the characteristics of the irrigation area. In summary, this article used the irrigation area of the lower Amudarya River as the research object and summarized the research questions into the following two aspects: 1. What were the characteristics of the temporal and spatial distributions of groundwater in the irrigation area in recent years and the reason for their formation? 2. What are the problems posing threats to regional groundwater? How can these problems be quantified? The key point of the research is also in this part.

To date, most studies on the sustainability of groundwater have focused on the ecological water level (Shuixian et al., 2011). Common methods used to determine the ecological water level can be divided into three categories: ecological survey statistical analysis, model calculation analysis, and remote sensing statistical analysis (Jiaqi et al., 2021). However, in arid areas, due to the scarce precipitation, the soil water in the unsaturated zone in the soil is weakly affected by precipitation infiltration. The impact of precipitation is generally limited to the ground surface or intercepted by vegetation, 
and soil water mainly comes from phreatic evaporation (Wang et al., 2020). Under the action of capillary force during diving, the soil water moves upwards and is either absorbed and utilized by the roots of vegetation or directly overflows. The concept of diving influence can explain ecological problems such as desertification, secondary salinization in arid areas, and differences in vegetation coverage due to different water replenishment with a more reasonable mechanism. The maximum height of capillary rise is also a critical point for quantitative research on different ecological problems in arid areas. Hydrological conditions can provide the basis. Therefore, this paper used the capillary method to calculate the area affected by diving and established the ecological water level standard.

In terms of trend analysis methods, most researchers use geostatistics as a water resource management and decision-making tool to reveal the temporal and spatial structures of groundwater level fluctuations (Buchanan and Triantafilis, 2009). These methods include the Mann-Kendall test method, and the wavelet analysis method is widely used in the trend and periodic analysis of various factors, which can effectively identify and analyse the target factors with more prominent changes. Inverse distance weighting (IDW) and stochastic methods are commonly used for groundwater level maps. IDW and stochastic methods (Varouchakis and Hristopulos, 2013) show similar performance. The IDW model is a fast, intuitive, non-intensive geostatistical deterministic method that is widely used in groundwater level mapping. In summary, using the M-K trend test, wavelet period analysis method, and IDW method, this article describes the spatial and temporal distribution characteristics of groundwater in the 
lower Amudarya River irrigation area and quantifies the degree of influence of climate change and human activities on regional groundwater. Additionally, the maximum height of capillary rise (capillary method) is used to establish ecological water level standards to diagnose and quantify the temporal and spatial distributions of regional groundwater resources, aiming to provide a target basis and theoretical basis for the sustainable management and regulation of regional groundwater. 


\section{Materials and methods}

\subsection{Study area}

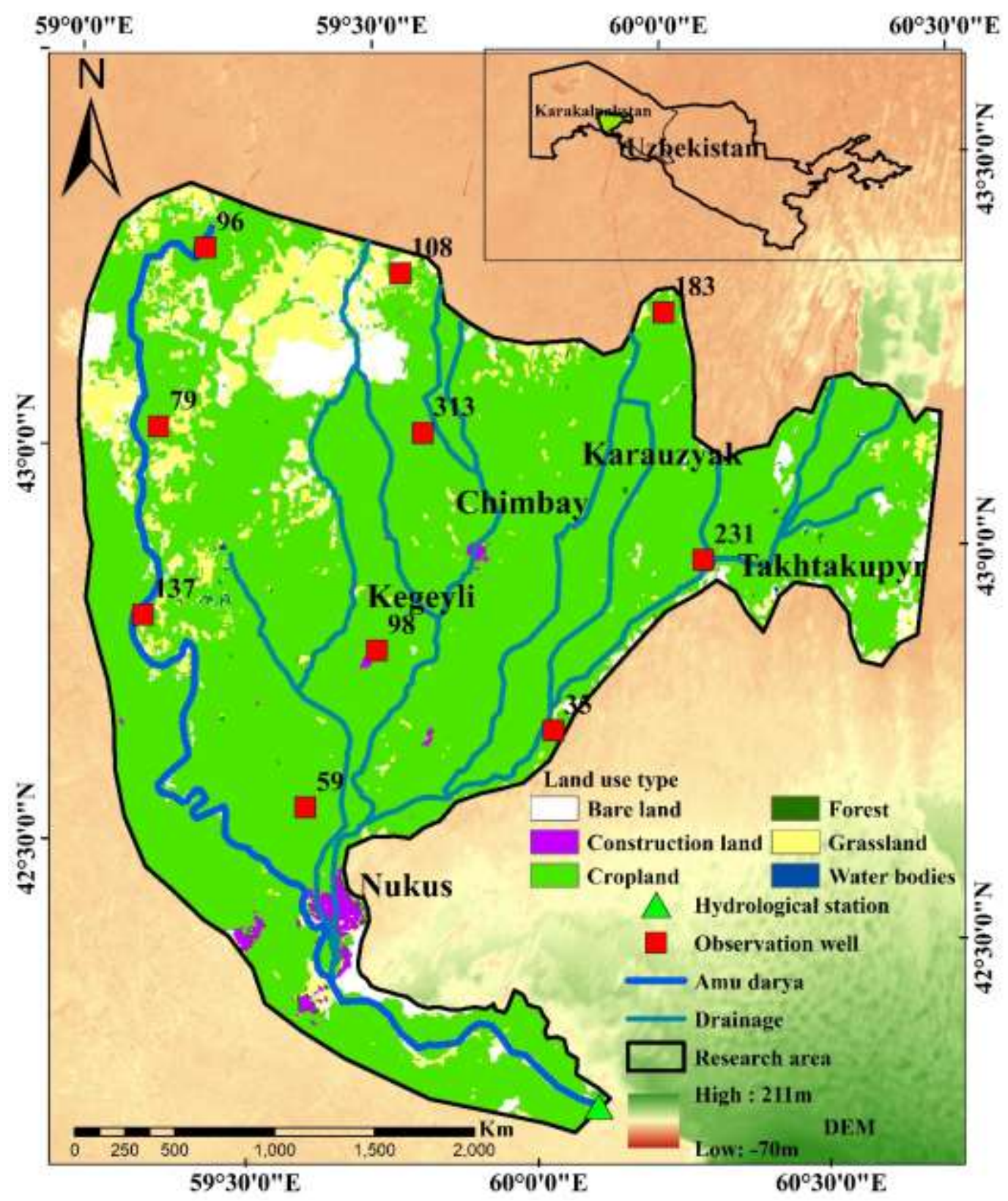

Figure 1 Geographical location, land use type, elevation, groundwater

observation point and distribution map of the river system in the study area

The study area is located in a typical agricultural irrigation area $\left(39.56^{\circ} \mathrm{N}\right.$, $59.16^{\circ} \mathrm{E}-42.13^{\circ} \mathrm{N}, 74.77^{\circ} \mathrm{E}$ ) in the lower reaches of the Amudarya River basin in Uzbekistan in Central Asia, adjacent to the South Aral Sea in the north and 
Turkmenistan in the south. The centre of the irrigation area is approximately $125 \mathrm{~km}$ from the lake basin of the South Aral Sea, and the shortest distance is approximately 75 $\mathrm{km}$. The total altitude of the region is high in the south and low in the north, with the highest altitude of $221 \mathrm{~m}$ in the south and the lowest altitude of $-70 \mathrm{~m}$ in the north. The total area of the irrigated area north of Yonukus is relatively flat, with an elevation difference of only 5-10 m. The Amudarya River runs through the whole irrigated area from south to north and serves as an important water supply source for the whole irrigated area. As a result, only a small amount of river water has flowed into the Aral Sea since the 1980s, and most of the water resources are used for agricultural irrigation in Nukus. Different kinds of wheat and cotton are the main agricultural crops in the region, while rice, corn, alfalfa and other crops are rarely planted. The backwards irrigation methods in the region are still mainly dominated by low-efficiency waterconsuming flood irrigation. The annual precipitation in this region is less than $200 \mathrm{~mm}$, mainly occurs in summer, and has shown a decreasing trend in recent years. The evapotranspiration of cultivated land in the growing season is between $700 \mathrm{~mm}$ and $1100 \mathrm{~mm}$ (Liu et al., 2020). The seasonal and intraday temperature differences are significant, with the lowest temperature between $-1.4{ }^{\circ} \mathrm{C}$ and $4{ }^{\circ} \mathrm{C}$ and the highest temperature reaching $30{ }^{\circ} \mathrm{C}$. The regional soil composition is mainly clay particles, and the aquifer of shallow groundwater in the irrigated area is approximately 0.4-5 m deep.

There is a hydrological station (Shmambay) located at the edge of the study area, and it is the last observation station in the lower reaches of the Amudarya River. There are also two meteorological stations in the study area, Nukus and Chimbay. However, 
there are more groundwater observation wells in the research area, and we picked out the ten different geographical locations of groundwater observation wells as feature points (in order to ensure the results available for other institutions for subsequent research can use the station number), which are used in the following research results on the description of the spatial distribution of groundwater.

\subsection{Data availability}

The data used in the study mainly included hydrological data, meteorological data, socioeconomic data, land use data and soil data. Hydrological data also included observation well groundwater data, average groundwater level data of an administrative region, and flow data from the Shmambay hydrological station. Meteorological data included temperature, precipitation and potential evapotranspiration. Socioeconomic data included population, agricultural output and agricultural growth rate. We plotted all data name sources and time scales, as shown in Table 1:

Table 1 Source and introduction of the data required for research

\begin{tabular}{|c|c|c|}
\hline Type & Name & Data introduction \\
\hline \multirow{3}{*}{ Hydrology } & $\begin{array}{l}\text { Groundwater data from } \\
\text { observation wells }\end{array}$ & \multirow{3}{*}{ Station, Monthly, 1990-2020 } \\
\hline & $\begin{array}{c}\text { Groundwater data from regional } \\
\text { average }\end{array}$ & \\
\hline & Run off & \\
\hline \multirow{3}{*}{ Meteorological } & Precipitation & \multirow{3}{*}{$\begin{array}{c}\text { Cru, Monthly, } 0.5^{\circ} \times 0.5^{\circ}, 1990-2020 \\
\text { http://data.ceda.ac.uk/badc/cru/data/cru_ts/ }\end{array}$} \\
\hline & Temperature & \\
\hline & Potential evapotranspiration & \\
\hline Socioeconomic & Population & \\
\hline
\end{tabular}




\begin{tabular}{|c|c|c|}
\hline & Agricultural production & Statistics, Yearly, 2000-2020 \\
\cline { 2 - 2 } & Agricultural growth rate & https://stat.uz/en/official- \\
& & statistics/metadata \\
\hline Land use & & $300 \mathrm{~m}$, Yearly, 2000-2020 \\
& & European Space Agency \\
\hline Soil & & HWSD \\
\hline
\end{tabular}

Groundwater data were used to study the spatial and temporal differences in groundwater at the annual and monthly scales. The groundwater observation point data were used to reflect the spatial variation in the regional groundwater and to make a regional groundwater distribution map. The study of regional integrity is based on the average value of regional groundwater because the variables are complementary and can be used to show the spatial and temporal changes in regional groundwater from different perspectives.

The data for the Amudarya River and meteorological socioeconomic data were used in the attribution analysis of the spatiotemporal changes in groundwater. Due to the lack of meteorological station data in the study area, the CRU TS4.04 data released by the Climatic Research Unit (CRU) of The University of East Anglia were used instead. The availability data in our study area has been demonstrated by previous research results (Chanjuan et al., 2021).

Land use data were derived from the GlobCover dataset of the European Space Agency (ESA), which has been widely used in various studies. This study used this dataset to extract the change in cultivated land area in the study area, aiming to determine the reasons for the spatiotemporal changes in groundwater. 
The soil data were based on the soil type in the World Soil Database (HWSD) of the Food and Agriculture Organization of the United Nations (FAO). The soil dataset has also been used in a number of studies and the type of soil in our study area is mainly clay. This study used this dataset to study the composition of regional soil particles to generate ecological water level limits by the capillary method.

\subsection{Research methods}

\subsubsection{Ecological water level determination method}

The ecological water level is widely used in the study of groundwater sustainability. During the development and utilization of groundwater resources and agricultural irrigation, the depth of the water level should be maintained within a certain range. The upper limit of this range is the water level that causes the strong evaporation during diving, causing salt accumulation in the surface soil and salinization. The lower limit is the water level that leads to the lack of ecological water in the area and causes the degradation of vegetation. This reasonable range of groundwater level changes is defined as the groundwater ecological water level. 


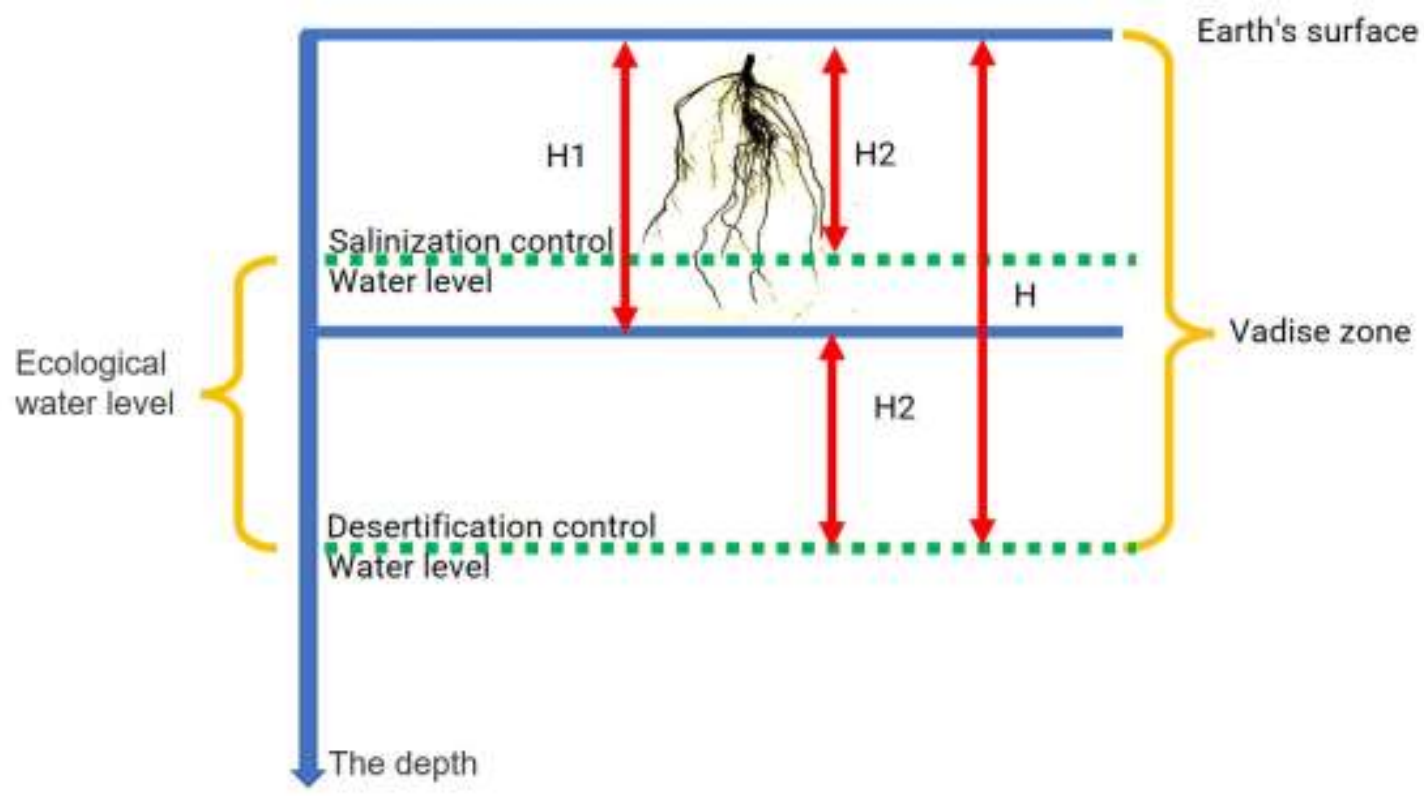

Figure 2 Structural principle of the vadose zone for groundwater recharge vegetation and the significance of the ecological water level

The principle of the capillary method is based on the abovementioned groundwater replenishment for vegetation. The lowest condition for vegetation to absorb water should be the contact between the phreatic impact layer and the root layer when the vegetation root system is tangent to the phreatic influence layer (Honglang et al., 2008). The groundwater depth corresponding to the intersection of the root action layer and the phreatic influence layer is the critical burial depth (the control water level for desertification), and the critical burial depth $\mathrm{H}$ is equal to the sum of the thickness of the vegetation root layer $H_{1}$ and the thickness of the phreatic influence layer $H_{2}$ :

$$
H=H_{1}+H_{2}
$$

The two most important physical quantities for determining the critical depth are the thickness of the phreatic impact layer $\mathrm{H}_{2}$ and the thickness of the vegetation root layer $H_{1}$. The condition for groundwater to recharge vegetation is that the depth of 
groundwater $h$ must meet: $h<H$.

The maximum thickness $H_{2}$ of the phreatic impact layer is also the maximum height at which shallow groundwater rises due to capillary forces, so it can be used as the upper boundary of the ecological water level (the control water level for salinization). The calculation method of the maximum rising height of capillary water is based on the formula proposed by Laplace. The calculation of the maximum rising height of soil capillary water can also be considered as the maximum thickness $\mathrm{H}_{2}$ of the diving-affected layer. The basic formula is as follows (Mingan, 2006):

$$
H_{2}=\frac{2 \gamma}{\rho g R}
$$

where $H_{2}$ is the rising height of the capillary tube $(m) . \gamma$ is the coefficient of soil water surface tension $(\mathrm{N} / \mathrm{m})$, which is related to temperature and can be found in a soil physics table; $R$ is the effective capillary pore diameter of the soil $(m)$ based on the type of soil used to take empirical parameters; $\rho$ is the density of water $\left(\mathrm{kg} / \mathrm{m}^{3}\right)$; and $g$ is the acceleration due to gravity $\left(\mathrm{m} / \mathrm{s}^{2}\right)$.

Previous studies have evaluated this method (Wang et al., 2020). For our research, we applied this method to calculate the upper bound $\left(H_{2}\right)$ and lower bound $(H)$ of the ecological water level.

\subsubsection{Mann-Kendall}

Mann-Kendall (M-K) tests are usually used to detect a series of long-term trends in climate data or hydrological data (Alashan, 2020). The main advantage of the M-K test is that the test does not require samples to follow a certain distribution and is not disturbed by a few outliers. The original assumption $(\mathrm{H} 0)$ of the $\mathrm{M}-\mathrm{K}$ test is that there 
is no trend or sequence correlation with the alternative hypothesis $(H 1)$ in the sample being analyzed, and the alternative hypothesis assumes that the monotonic trend increases or decreases. In this study, the M-K test was applied to the trend analysis of the groundwater level. The test statistic $S$ is calculated as follows:

$$
\mathrm{S}=\sum_{k=1}^{n-1} \sum_{j=k+1}^{n} \operatorname{Sgn}\left(X_{j}-X_{k}\right)
$$

Furthermore, $\quad \operatorname{Sgn}\left(X_{j}-X_{k}\right)=\left\{\begin{array}{cc}+1 & \left(X_{j}-X_{k}\right)>0 \\ 0 & \left(X_{j}-X_{k}\right)=0 \\ -1 & \left(X_{j}-X_{k}\right)<0\end{array}\right.$

where $S$ is a normal distribution with a mean of $0, V_{a}(S)=n(n-1)(2 n+5) / 18$. When $\mathrm{n}>10$, the standard normally distributed system variable can be calculated by the following formula:

$$
\mathrm{Z}= \begin{cases}\frac{S-1}{\sqrt{V_{a}(S)}} & S>0 \\ 0 & S=0 \\ \frac{S+1}{\sqrt{V_{a}(S)}} & S<0\end{cases}
$$

Therefore, in the trend of the bilateral inspection, at a given confidence level, if, the $|Z| \geq Z_{1-a / 2}$ null hypothesis is unacceptable, namely, at the $a$ confidence level, the time series data exhibit an obvious up or down trend. For the statistic $Z$, greater than 0 is an upwards trend; less than 0 is a downwards trend. When the absolute value of $Z$ is greater than or equal to $1.28,1.64$ and 2.32 , it indicates that it has passed the significance test at the levels of $90 \%, 95 \%$ and $99 \%$, respectively.

When the M-K test is further used to test sequence mutations, the test statistics were different from the above $Z$ and an order column was constructed:

$$
\mathrm{S}_{k}=\sum_{i=1}^{k} \sum_{j}^{i-1} a_{i j} \quad(k=2,3,4, \cdots, n)
$$


Furthermore: $\quad a_{i j}=\left\{\begin{array}{ll}1 & X_{i}>X_{j} \\ 0 & X_{i}<X_{j}\end{array} \quad 1 \leq j \leq i\right.$

Define statistical variables:

$$
U F_{k}=\frac{\left[S_{k}-E\left(S_{k}\right)\right]}{\sqrt{\operatorname{Var}\left(S_{k}\right)}} \quad(k=1,2, \cdots, n)
$$

In the formula: $\quad E\left(S_{k}\right)=\frac{k(k+1)}{4} ; V_{a r}\left(S_{k}\right)=k(k-1)(2 k+5) / 72$

where $U F_{k}$ is the standard normal distribution; and at the given significance level $a$, if $\left|U F_{k}\right| \geq U_{a / 2}$, then there is an obvious trend change in the sequence. Time series $\mathrm{X}$ could be arranged in the reverse order and calculated using the formula above to obtain the following:

$$
\left\{\begin{array}{l}
U B_{k}=-U F_{k} \\
k=n+1-k
\end{array} \quad(k=1,2, \cdots, n)\right.
$$

By analysing the statistical sequences $U F_{k}$ and $U B_{k}$, we can further analyze the trend change of sequence $\mathrm{X}$ and specify the time of mutation and the region of mutation. If the value of $U F_{k}$ is greater than 0 , the sequence shows an upwards trend. A value less than 0 indicates a downwards trend; however, when the value exceeds the critical line, it indicates a significant upwards or downwards trend. If the $U F_{k}$ and $U B_{k}$ curves intersect and the intersection is between the critical lines, then the time corresponding to the intersection is the time when the mutation begins..

\subsubsection{Inverse distance weighting method}

The inverse range-weighted interpolation algorithm is referred to as the IDW algorithm, in which the value of each sampling point contributes to the interpolation point with different weights, and the weight is related to the distance between the sampling point and the interpolation point (Kewei et al., 2021). The IDW algorithm is 
essentially a weighted average. It first determines the weight of each sample point, multiplies the value of each sample point and sums the results to obtain the total value, and divides by the sum of the weight of each sample point. Suppose $Z_{i}$ is the value of known sample points, $W_{i}$ is the corresponding weight of known sample points, and $Z_{p}$ is the interpolation of points to be solved, which is calculated as follows:

$$
\mathrm{Z}_{P}=\frac{\sum_{i=1}^{n}\left(Z_{i} \times W_{i}\right)}{\sum_{i=1}^{n} W_{i}}
$$

The weight $W_{i}$ in the inverse distance weighting method is determined by the following formula:

$$
W_{i}=\left(\frac{1}{d_{i}}\right)^{u}
$$

In Formula (12), $d_{i}$ is the distance between the interpolation point and the known sample point; $u$ is the weight exponent. The higher the weight index is, the smoother the interpolation result is. $u$ is the control parameter. The larger the $u$ value is, the faster the weight decays with increasing distance. In contrast, the smaller $u$ is, the slower the weight decays with increasing distance. Generally, $u$ is 1-3(Stein, 2009). In this study, the IDW method was applied to map the spatial distribution of regional groundwater.

\subsubsection{Coefficient of variation}

The coefficient of variation is a normalized measure of the degree of dispersion of the probability distribution, which is defined as the ratio of the standard deviation to the average value (Lande, 1977):

$$
\mathrm{CV}=\frac{\sigma}{\mu}
$$

Coefficient of variation (also known as dispersion coefficient) is a normalized 
measure of dispersion degree of probability distribution. The coefficient of variation is defined only when the mean is not zero, and generally applies when the mean is greater than zero. Unlike the standard deviation, the coefficient of variation can be used to compare the degree of dispersion of two groups of different dimensions or very different data. The larger the $\mathrm{CV}$ value, the greater the degree of dispersion within the data group, and the wider the spatial range representing the data distribution. In this article, we use the $\mathrm{CV}$ value to represent the volatility of groundwater changes.

\subsubsection{Pearson correlation analysis}

The correlation coefficient is a descriptive statistical indicator first designed by statistician Pearson, which refers to the degree to which a change in one variable corresponds to another (Pearson, 1901). The correlation coefficient has been widely used in various fields of research. We use the correlation coefficient to explore the impact of climate factors such as temperature, precipitation, evapotranspiration and human activity factors such as cultivated land and population on groundwater in irrigated areas.

$$
\mathrm{R}(\mathrm{X}, \mathrm{Y})=\frac{\operatorname{Cov}(X, Y)}{\sqrt{\operatorname{Var}[X] \operatorname{Var}[Y]}}
$$

where $\operatorname{Cov}(X, Y)$ is the covariance of $X$ and $Y, \operatorname{Var}[X]$ is the variance of $\mathrm{X}$, and $\operatorname{Var}[Y]$ is the variance of $\mathrm{Y}$. 


\section{Results}

\subsection{Analysis of the change in the temporal and spatial distribution characteristics}

\section{of groundwater}

Based on the measured data of groundwater observation wells, this section used the inverse distance weighting method, Mann-Kendall trend test method, wavelet periodicity analysis method and coefficient of variation method to explore the groundwater in the research area from the three aspects of time change trend, periodicity and volatility. The characteristics of the temporal and spatial distributions change on a yearly scale and monthly scale changes of groundwater occurred in a statistical area.

The inverse distance weighting method was applied to the study of the spatial and temporal distributions of regional groundwater levels, and the annual average spatial distribution of groundwater levels in 2000 and 2019 is shown in Figure 3. The regional groundwater levels were mainly affected by elevation and appeared to be high in the south and low in the north. The groundwater level varied significantly with latitude, and the water level varied from $107.3 \mathrm{~m}$ to $41.87 \mathrm{~m}$ from south to north. With the change in time, since the changes in the elevation of the study area were much greater than the changes in the groundwater level, the changes in the groundwater level in the two years in the figure are not obvious, but the years 2019 and 2020 could be compared for the study area. The areas of low water level in the central irrigation district have been significantly reduced, and the regional average groundwater level has increased significantly. 


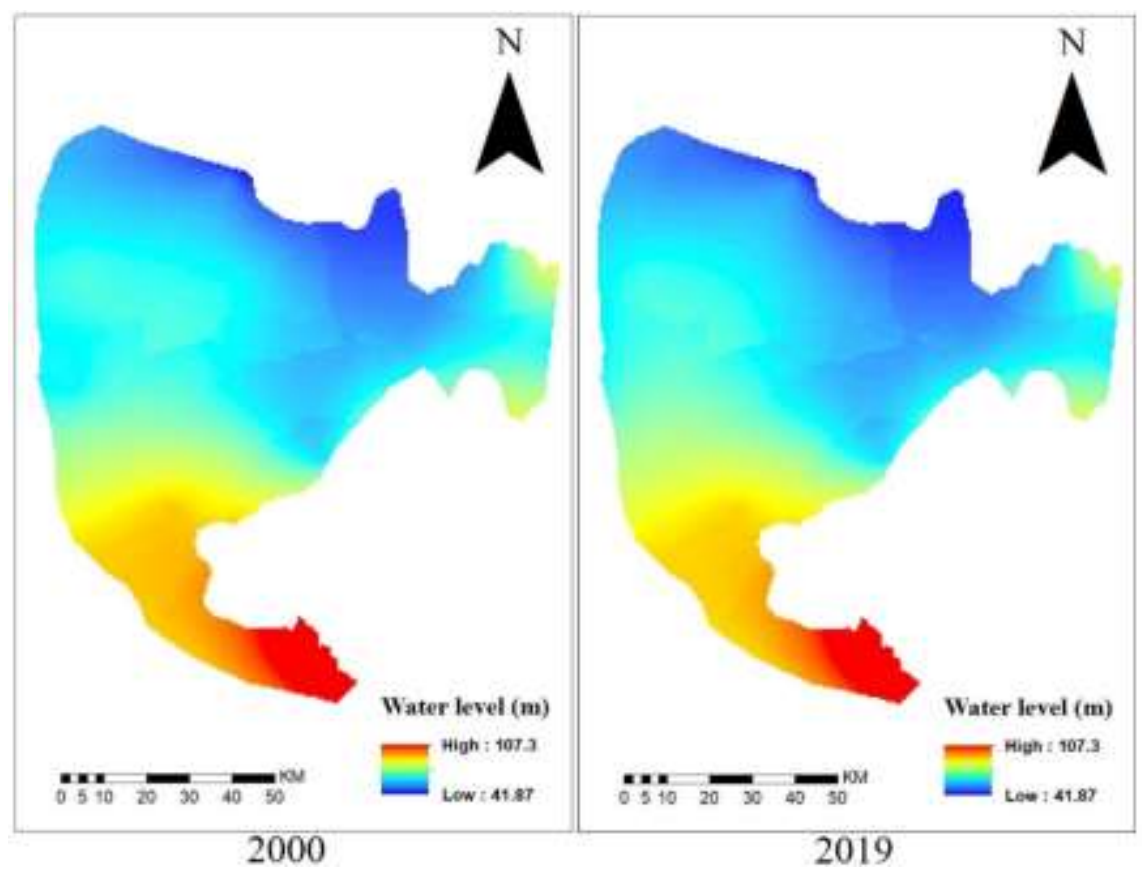

Figure 3 Groundwater level distribution maps of the study area in 2000 and 2019 based on the inverse distance weighting method

The Mann-Kendall test method was applied to the mutation test of the annual average groundwater level data of 10 groundwater level observation points in the study area to determine how the groundwater level in the area has changed since 1999. The groundwater level changes within the irrigation area showed strong temporal and spatial heterogeneity (Figure 4). Except for points 183 and 231, which had high similarity, the mutation time and future change trends of other points were not the same. Even the points that were spatially closer did not have any similarities (e.g., points that were all located by the river, points that are all located in the north). Among all points, 35, 79, 98,183 , and 231 showed an upwards trend with an average increase of $0.04 \mathrm{~m} / \mathrm{a}$; points 35,183 , and 231 had the most significant upwards trend, with the highest increase of $0.09 \mathrm{~m} / \mathrm{a}$; points $59,96,108,137$, and 313 showed a downwards trend with an average decline of $0.02 \mathrm{~m} / \mathrm{a}$; and the downwards trend of points 108 and 137 was the most 
significant and the largest decline was $0.04 \mathrm{~m} / \mathrm{a}$. The year of each point mutation varied from 1 (point 35, 79, 108, 137, 183, 231) to 7 (point 98). The years of mutation were generally distributed from 2002 to 2018 and were mainly concentrated from 2009 to 2016. For the average groundwater level of the entire region, the groundwater level in the study area has shown a slight rise since 2002, with an upwards trend of approximately $0.015 \mathrm{~m} / \mathrm{a}$, and the variation range of each observation point was between -0.054 and $0.098 \mathrm{~m} / \mathrm{a}$. Using wavelet analysis for the periodic analysis of the regional groundwater, the results showed that the annual average groundwater level in the region had no significant periodicity during 2000-2020, which was consistent with the wavelet analysis results from various observation wells. All the results showed that there was no periodicity in the changes of the regional groundwater level on the annual scale, so the results of the wavelet periodicity analysis of each single well are not listed individually. 

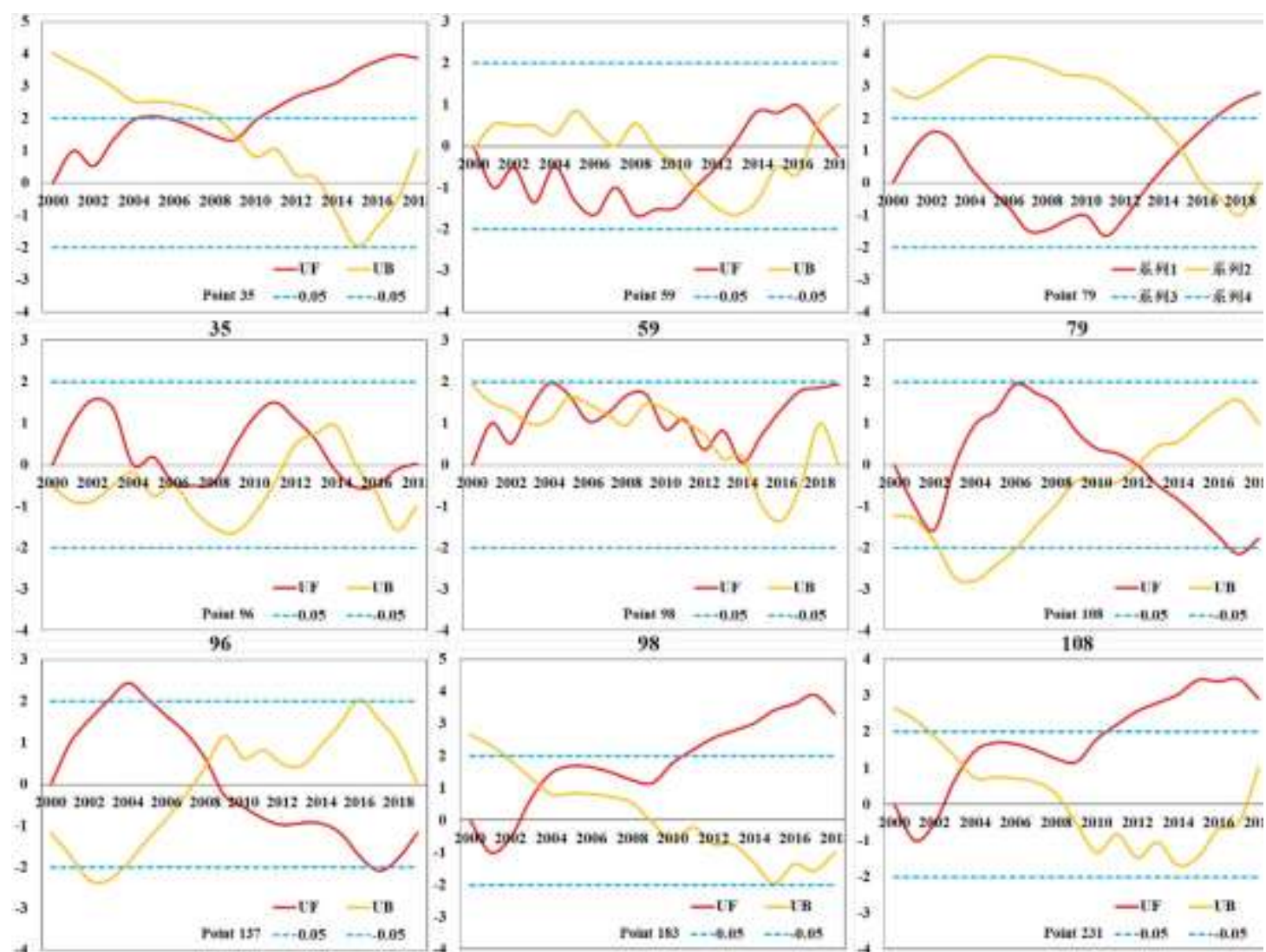

10
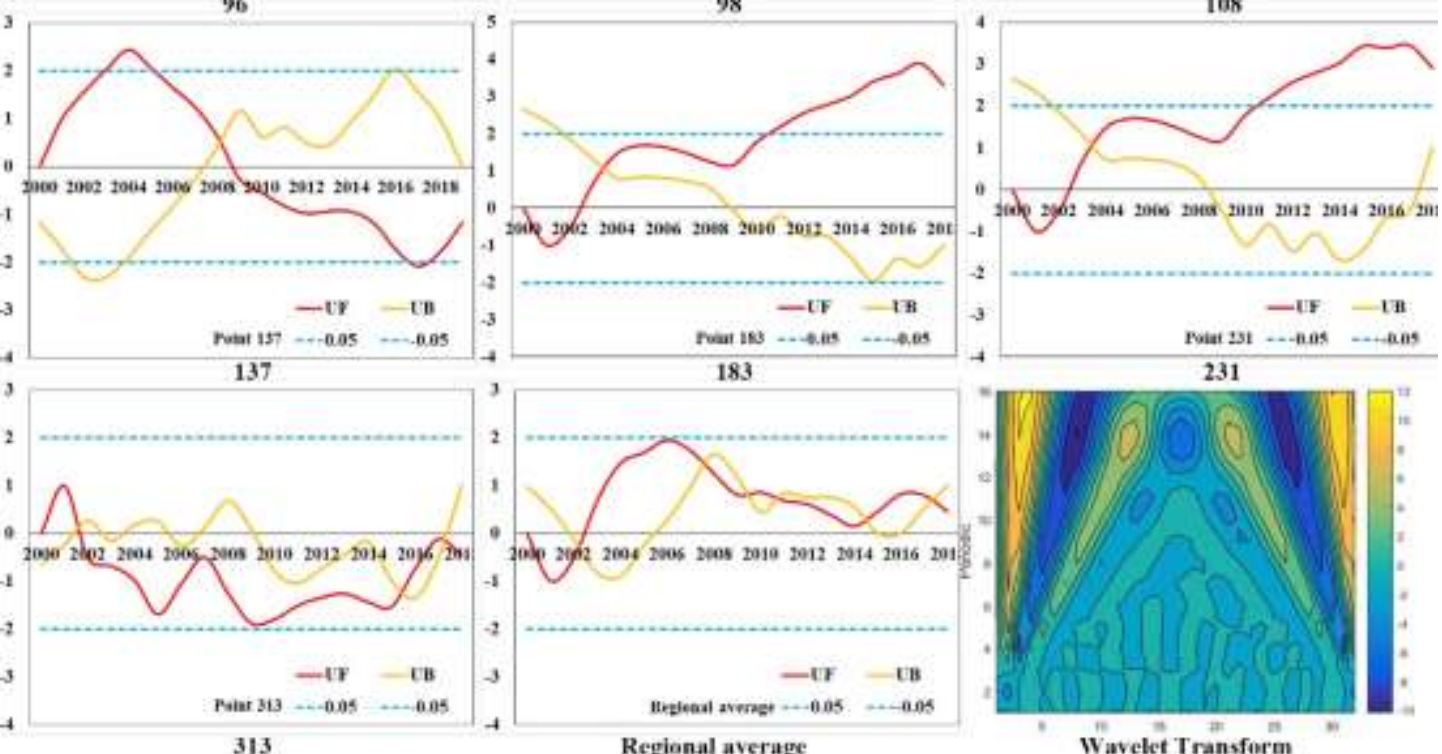

Figure 4 The M-K test of the changes in water observation points in various

\section{places from 2000 to 2020 and the wavelet periodic analysis of the regional}

\section{average water level}

The monthly scale changes were similar to those at the annual scale, and the distribution of the groundwater level still reflected strong temporal and spatial heterogeneity (Figure 5). It is worth noting that all or most of the months showed an increasing trend at points $35,79,98,183$, and 231. Among them, point 35 had the largest growth rate in April $(0.11 \mathrm{~m} / \mathrm{a})$. Most of the months showed a decreasing trend at points 
59 and 137, and point 137 had the largest rate of decrease in April (-0.06 m/a). For the entire region, the groundwater level in each month except November $(-0.005 \mathrm{~m} / \mathrm{a})$ showed an increasing trend, with the highest growth rate in March (0.029 m/a). By dividing the 12 months into the irrigation period and the non-irrigation period, we found that the groundwater growth rate $(0.016 \mathrm{~m} / \mathrm{a})$ during the irrigation period (March to October) was approximately twice the growth rate of groundwater during the nonirrigation period (January, February, November, December). This result means that in the future, the range of groundwater changes during the year will be greater, and the groundwater level during the irrigation period will rise significantly. Next, we will analyse the variation range of groundwater depth at each point.

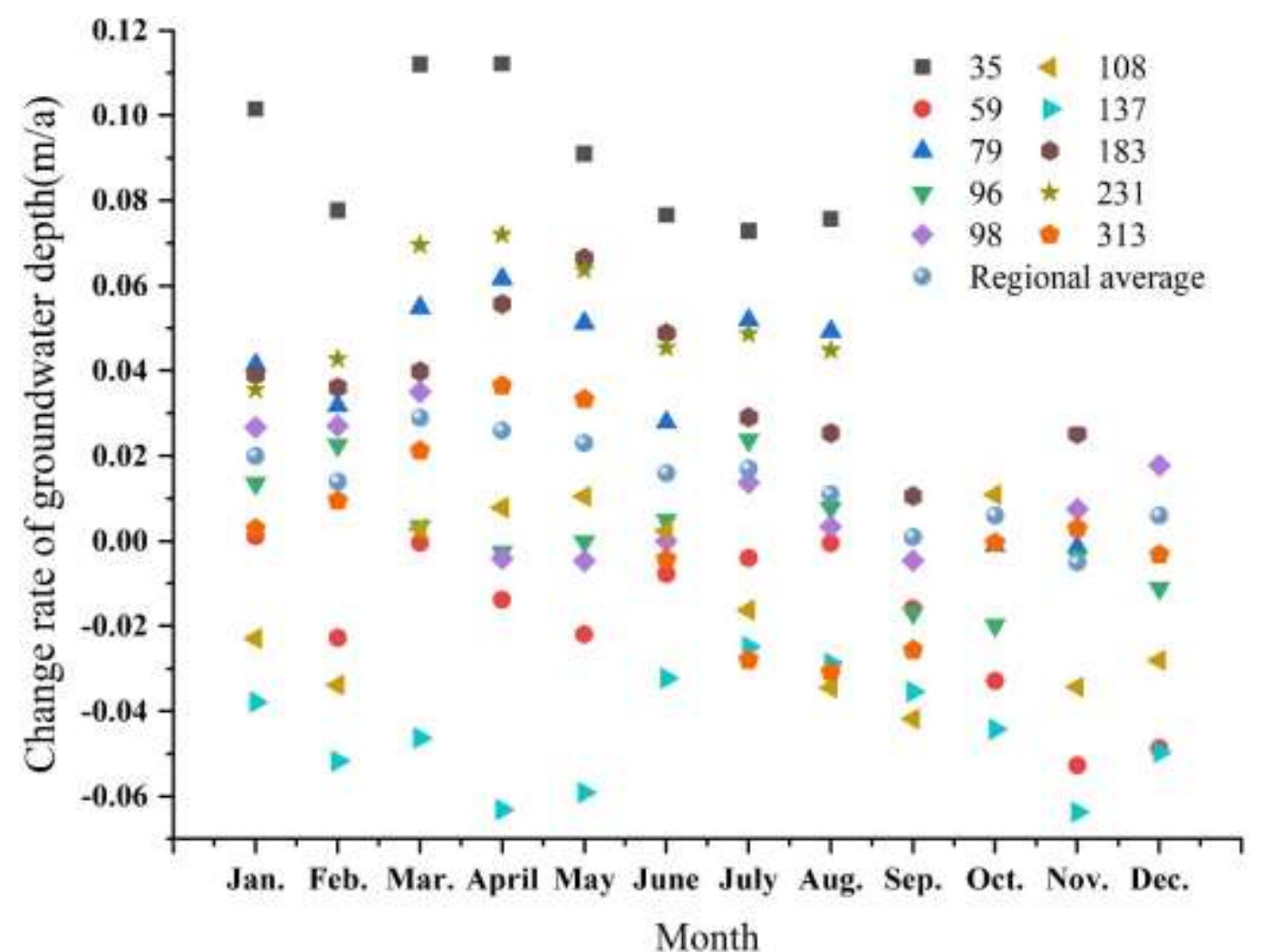

Figure 5 The change rate of the groundwater level at each observation point and the regional average groundwater level on a monthly scale from 1999 to 2020 
In terms of the monthly average groundwater depth at each point, the month in which the lowest value of the average groundwater level at each point occurred was not the same, but all were concentrated between April and August; the highest value was concentrated between November and February of the following year (Figure 6). With the exception of point 96 , all observation points showed that the average groundwater level during the irrigation period was lower than that during the non-irrigation period. The regional groundwater level rose significantly during the irrigation period, and the rise was the most significant at point 137 , which rose by approximately $1.2 \mathrm{~m}$ compared with the non-irrigation period. Regarding the average groundwater level of the entire region, at the same time as the start of irrigation activities, the regional groundwater level rose significantly starting in March, and the highest value appeared in July, exceeding the average water level of $0.64 \mathrm{~m}$ during the non-irrigation period, and showed a significant decreasing trend in September. The quartile point can be used as an important indicator to measure the volatility of the groundwater level. In terms of the fluctuation range, the difference in the position of the observation points was very obvious. Different points exhibited different ranges of fluctuations in different months. Almost all months had periods of maximum or minimum fluctuations at different observation points. The maximum fluctuation range appeared in May $(2.1 \mathrm{~m})$ at observation point 183 and in June $(2.2 \mathrm{~m})$ at observation point 137 , and the minimum appeared in May $(0.2 \mathrm{~m})$ at observation point 98 and in April $(0.2 \mathrm{~m})$ at observation point 79. For the whole area, the fluctuation range of groundwater in August was the largest $(1.1 \mathrm{~m})$, and the fluctuation range in May was the smallest $(0.34 \mathrm{~m})$. The 
volatility of the regional groundwater level was similar regardless of the irrigation period or the non-irrigation period, but the fluctuation range of $0.9 \mathrm{~m}$ in the irrigation period was slightly higher than the fluctuation range of $0.7 \mathrm{~m}$ in the non-irrigation period. As shown in the above results, we performed a linear regression analysis on the regional average water level on a monthly scale. The results showed that the groundwater level during the non-irrigation period and that during the irrigation period showed a slowly rising trend. Such a slow rising and rising volatility trend will cause the entire region to have a more extreme rise in groundwater level in the future. 


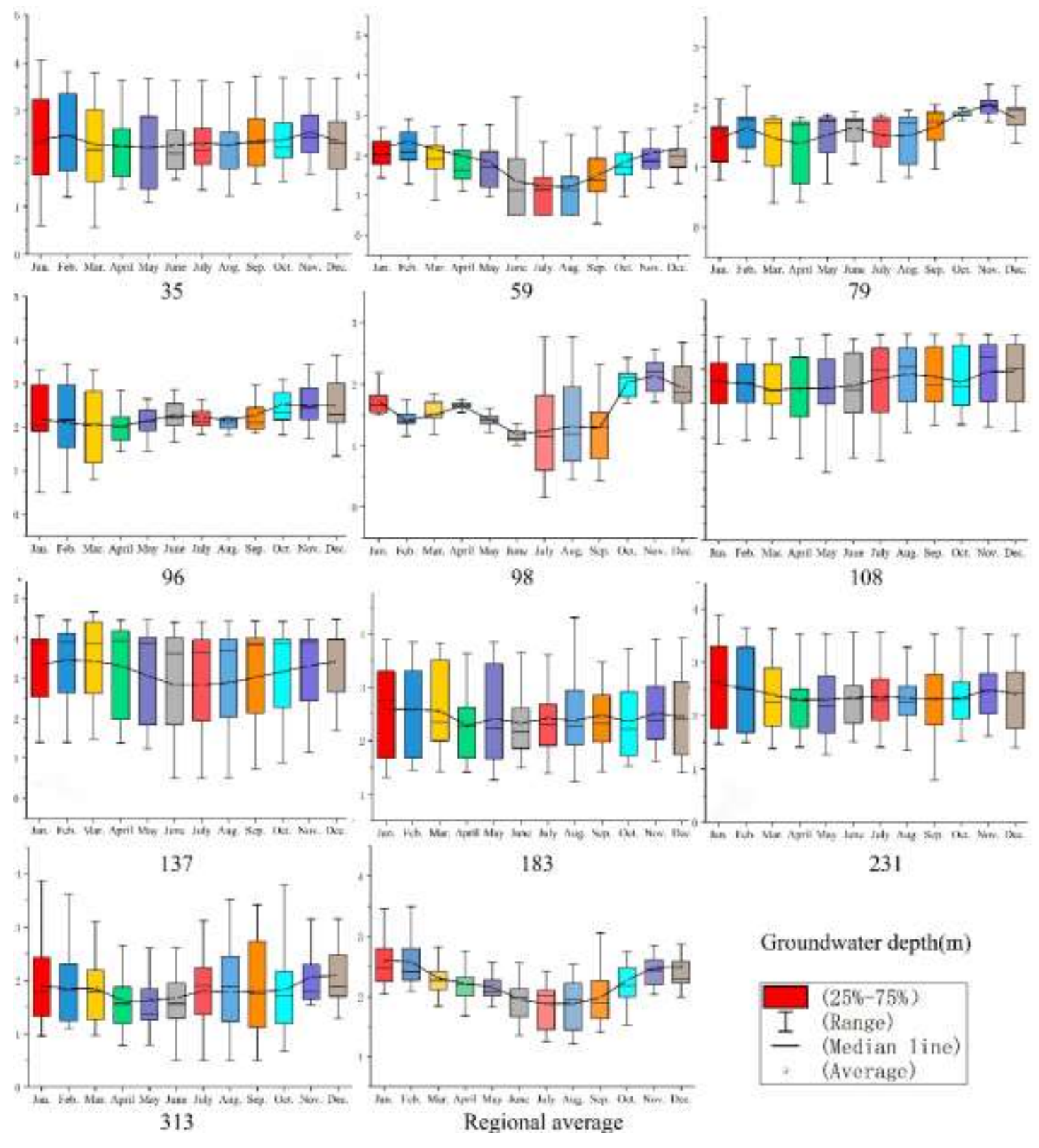

Figure 6 Monthly scale box-type statistical graphs of various groundwater observation points and regional average groundwater levels from 2000 to 2020

To verify this trend, we used the coefficient of variation (CV) to compare the degree of groundwater level changes in each year (Figure 7). The CV value of the regional average groundwater level during the period 1999-2020 showed a significant fluctuating increase, with an increase of approximately 0.0078/a. Especially after 2017, this result indicated that the volatility of the groundwater level during the year had 
gradually increased, and the degree of water level changes during the year had gradually increased.

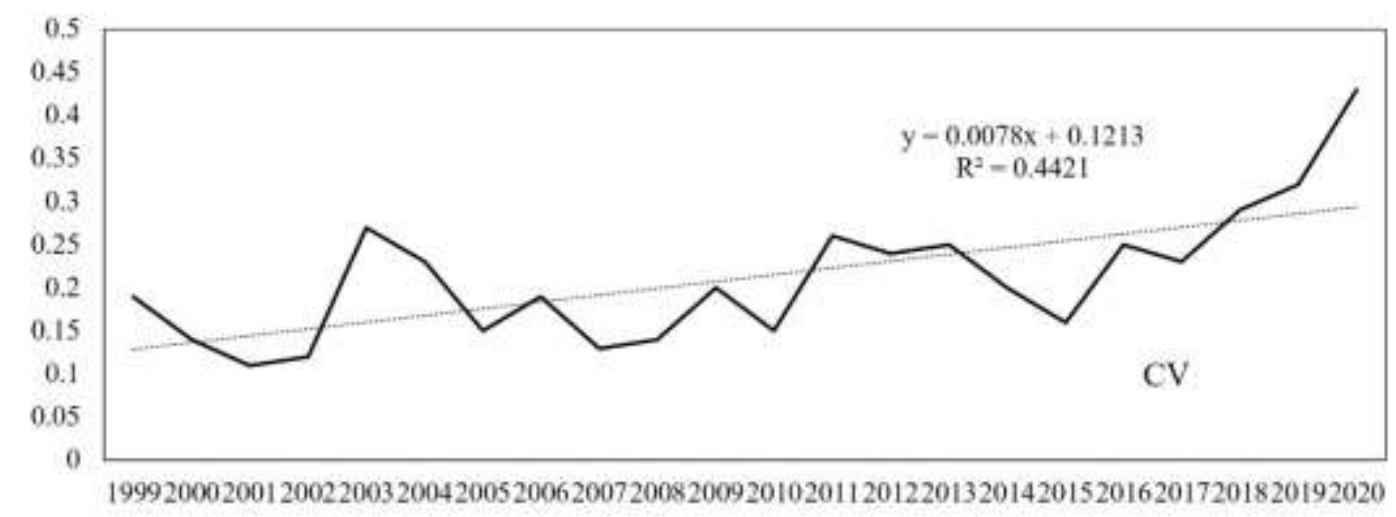

Figure 7 Linear graph of the coefficient of variation of regional groundwater during 1990-2020

\subsection{Attribution analysis of groundwater table changes}

The above research results showed that the change in groundwater level in the irrigation area generally showed strong temporal and spatial heterogeneity, and this temporal and spatial heterogeneity value had no significant periodicity or regularity. Based on the research background, the changes in the regional natural and human environment in the past 20 years were mainly concentrated on the increase in population, the expansion of arable land, and the frequent dry-up events of the Amudarya River. Therefore, in the context of climate change, to explore the reasons for the interannual and interannual temporal and spatial changes in the groundwater level, this article selected annual average temperature, precipitation, potential evapotranspiration, and Amudarya River discharge as natural factors and population, cultivated land area, and agriculture as influencing factors. The increase in output and agricultural output value were used as influencing factors of human activities. Using the method of correlation 
analysis, we explored the relationship between the influencing factors and the depth of groundwater and the $\mathrm{CV}$ value of groundwater changes during the year, as shown in Figure 8. In terms of human activity factors, the average groundwater level had a strong correlation with arable land area, agricultural output, and population. The correlation coefficients were $0.89,0.88$, and 0.84 . The $\mathrm{CV}$ value of groundwater change during the year also had the highest correlation with these three factors, but the ranking had changed by $0.56,0.67$, and 0.68 . Regarding the natural factors, both the average groundwater level and the CV value of the annual variation in groundwater had low correlations with various natural factors. The correlation between precipitation and the average groundwater level and the $\mathrm{CV}$ value of the annual variation in groundwater was the highest among natural factors. It was also only 0.49 and 0.21 . Human activities were the main factors affecting the regional average groundwater level and groundwater level volatility during the year, accounting for $67.6 \%$ and $78.9 \%$ of all influencing factors, while natural factors accounted for only $32.4 \%$ and $21.1 \%$.

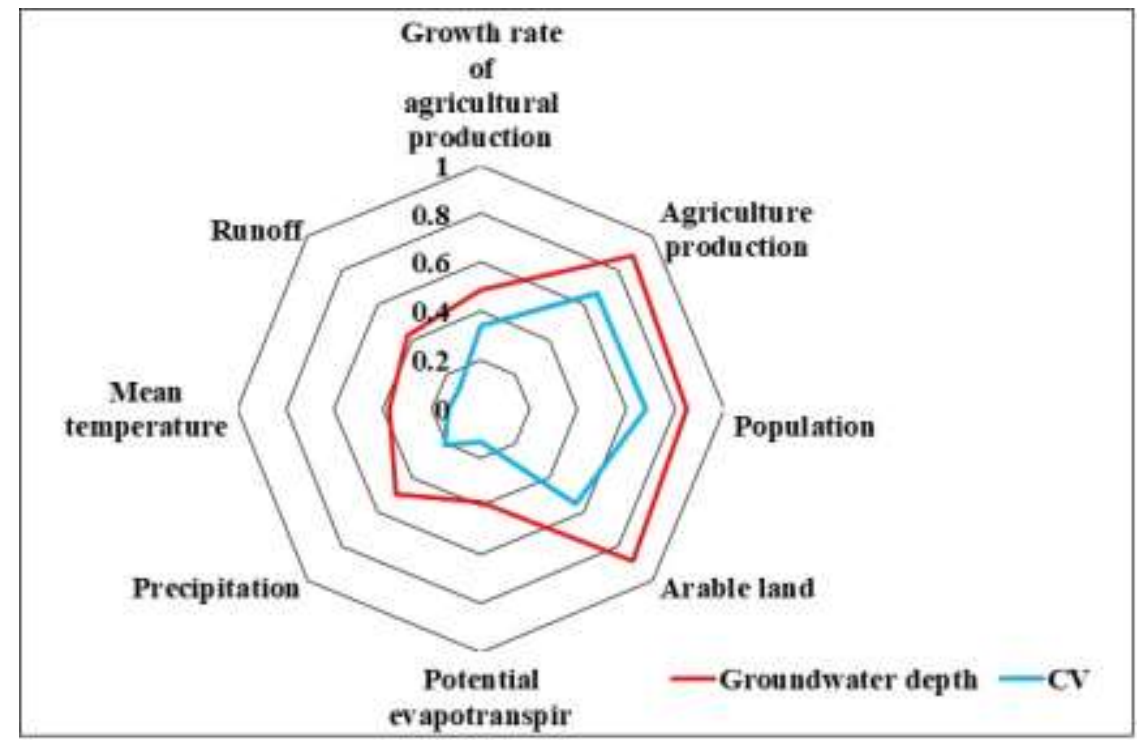

Figure 8 Analysis of the impact of natural and human activities on the 


\section{annual and interannual changes in groundwater}

\subsection{Regional groundwater sustainability analysis based on ecological water level}

A previous study showed that human activities have become the key factor affecting the groundwater level in irrigated areas. To ensure the sustainable development and regulation of regional groundwater resources, this section used the capillary method to calculate the regional ecological critical water level and used the monthly scale as the standard to identify regional groundwater resource utilization problems in the last 5 years.

The main cash crops and food crops in the study area are cotton and wheat, respectively, accounting for approximately $89 \%$ of the total cultivated area. Therefore, the ecological water level of cotton and wheat was calculated by the capillary method. According to the research data from Irrigation University of Uzbekistan and the Xinjiang Academy of Agricultural Sciences, the average main root depth of wheat and cotton in this irrigated area is in the range of $0.5-1 \mathrm{~m}$, and the soil water temperature is approximately $20{ }^{\circ} \mathrm{C}$ in the growing season of crops. Based on these data, $1 \mathrm{~m}$ was taken as the maximum average root depth of crops $H_{1}$, and the average tension coefficient $\gamma$ and average density $\rho$ of soil water at $20^{\circ} \mathrm{C}$ were determined to be $72.5 \times$ $10^{-3} \mathrm{~N} / \mathrm{m}$ and $996 \mathrm{~kg} \mathrm{~N} / \mathrm{m}^{2}$, respectively. Meanwhile, based on the World Soil Database (HWSD) constructed by the FAO and IIASA, the average effective capillary pore size of soil in irrigated areas was estimated to be approximately $0.0082 \mathrm{~mm}$ according to the soil type, and the upper and lower bounds of ecological water level were calculated as shown in Table 2. 
Table 2 The main values of the parameters needed for the calculation of the upper and lower bounds of the ecological water level

\begin{tabular}{|c|c|c|c|c|c|c|}
\hline $\begin{array}{l}\text { Maximum } \\
\text { average root } \\
\text { depth of } \\
\text { crops }\left(H_{1}\right)\end{array}$ & $\begin{array}{l}\text { Temperature } \\
\text { (T) }\end{array}$ & $\begin{array}{l}\text { Average } \\
\text { tension } \\
\text { coefficient } \\
(\gamma)\end{array}$ & $\begin{array}{l}\text { Water } \\
\text { density } \\
(\rho)\end{array}$ & $\begin{array}{l}\text { Average } \\
\text { effective } \\
\text { capillary } \\
\text { pore } \\
\text { diameter of } \\
\text { the soil (R) }\end{array}$ & $\begin{array}{l}\text { Upper } \\
\text { limit of } \\
\text { mean } \\
\text { ecological } \\
\text { water level } \\
\left.\qquad \mathrm{H}_{2}\right)\end{array}$ & $\begin{array}{l}\text { Lower } \\
\text { limit of } \\
\text { mean } \\
\text { ecological } \\
\text { water level } \\
(H)\end{array}$ \\
\hline $1 \mathrm{~m}$ & $20^{\circ} \mathrm{C}$ & $\begin{array}{l}72.5 \\
\times 10^{-3} \mathrm{~N} \\
/ \mathrm{m}\end{array}$ & $\begin{array}{l}996 \\
\mathrm{~kg} / \mathrm{m}^{3}\end{array}$ & $0.0082 \mathrm{~mm}$ & $1.78 \mathrm{~m}$ & $2.78 \mathrm{~m}$ \\
\hline
\end{tabular}

The ecological water level was between $1.78 \mathrm{~m}$ (salinization control limit) and $2.78 \mathrm{~m}$ (desertification control limit). We drew the relationship between the monthly average buried depth of all observation points from 1999 to 2020 as a line graph to determine the relationship with the ecological water level and selected points 79, 231, and 108 as the three different characteristic geographic locations that could simultaneously express these three situations, as shown in Figure 9. The results were consistent with the previous results. The relationship between the buried depth of each point and the ecological water level also showed strong temporal and spatial heterogeneity. We divided them into three situations: the points with the most months above the upper limit of the ecological water level $(59,79,96,313)$, the points with the most months between the ecological water level $(35,96,183,231)$, and the maximum number of months below the lower limit of the ecological water level $(108,137)$. The number of months between the ecological water levels during the change in the regional 
average groundwater level from 1999 to 2020 totalled 135 months, which was 14 months more than the number of months at the upper boundary of the ecological water level. Under the influence of human activities, the study area was usually higher than the ecological water level or aligned with the ecological water level. However, with the continuous increase in the volatility of the groundwater level since 2016, the duration of time in which the groundwater level was higher than the ecological water level also increased significantly, but there had also been a situation where the groundwater level was lower than the ecological water level. The above research showed that there was a risk of salinization of the regional groundwater due to excessively high water levels.
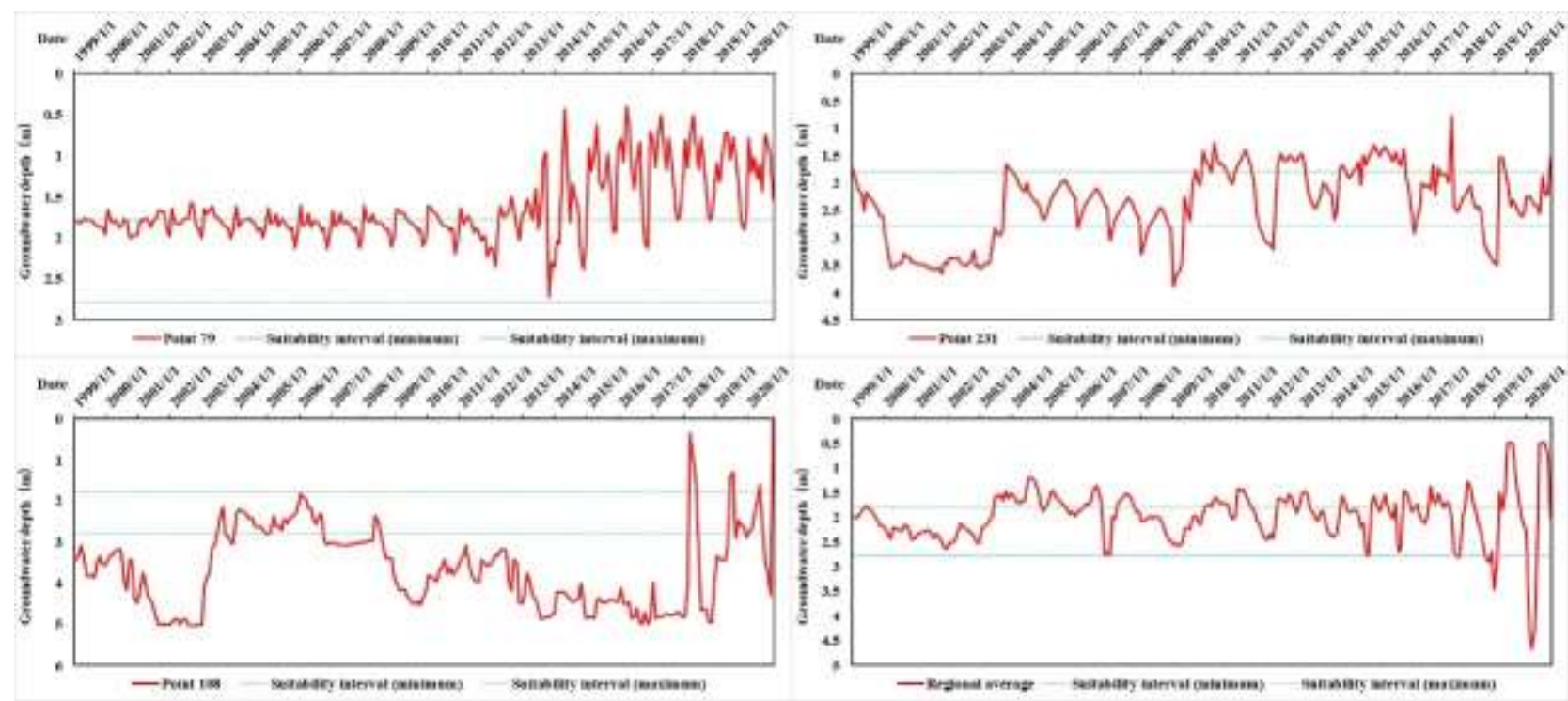

Figure 9 The relationship between feature points 79, 231, and 108 and the regional average groundwater level from 1999 to 2020

With the increase in groundwater level volatility, the range of changes in the relationship between groundwater depth and the ecological water level has increased in recent years. Thus, we predict that groundwater problems will also increase. To further distinguish the differences in the temporal and spatial distributions and diagnose the 
temporal and spatial distributions of groundwater resources in the region, we interpolated the monthly average water level data of the groundwater observation wells from 2016 to 2020 with prominent changes in the CV values using the IDW method. According to the ecological water level, we created five levels according to the principle of equidistance. Values from 1 to 5 , respectively, represented higher water level $(0.4 \mathrm{~m}-1.05 \mathrm{~m})$, high water level $(1.05 \mathrm{~m}-1.7 \mathrm{~m})$, located in the ecological water level range (1.7 m-2.7 m), low water level (2.7 m-3.4 m) and lower water level (3.4-4.1 $\mathrm{m})$, and all are shown in Figure 10. 

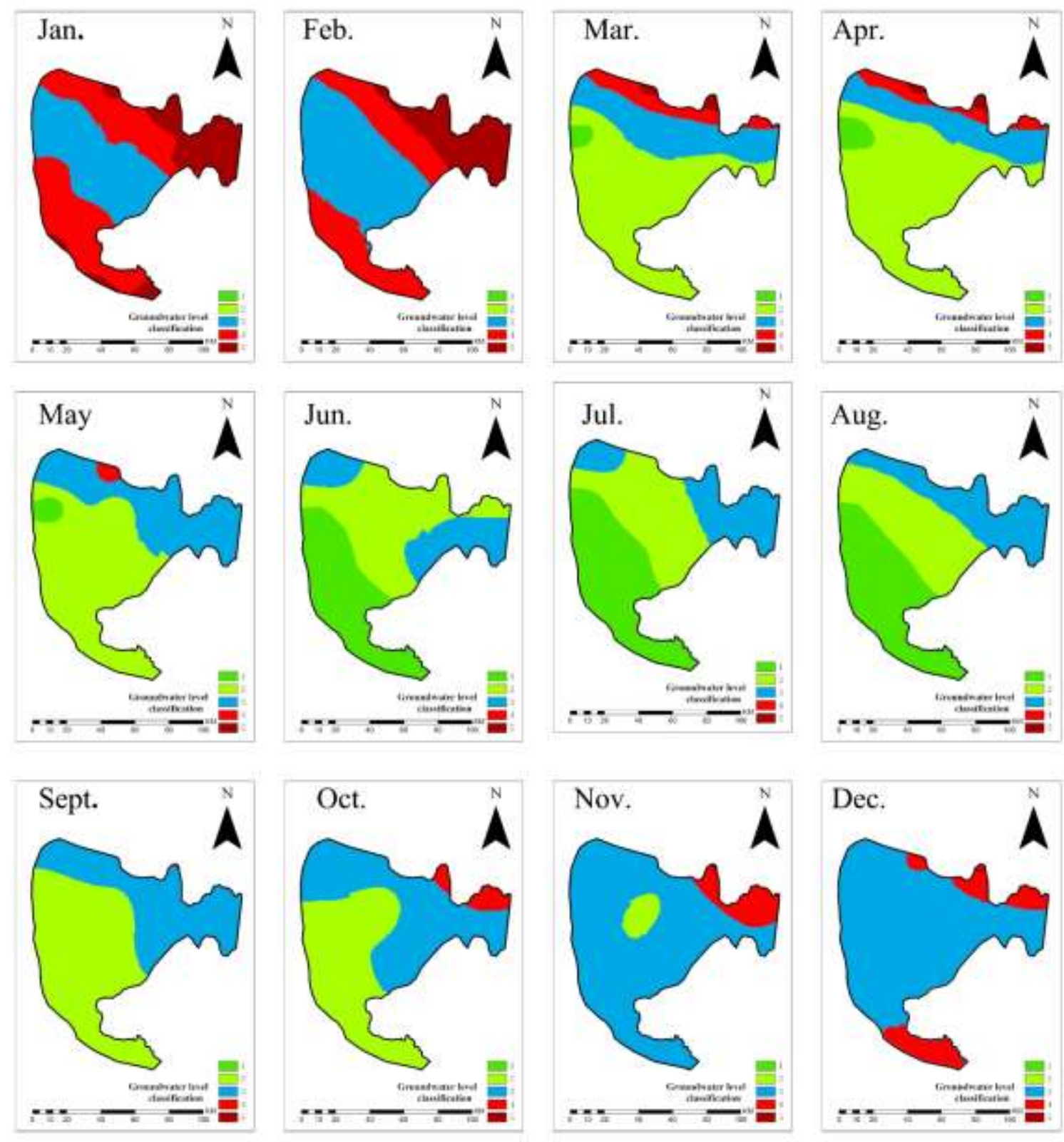

Figure 10 2016-2020 monthly scale classification of regional groundwater

\section{depth based on ecological water level}

The figure clearly shows that the temporal and spatial changes in groundwater changed suddenly in March, and the regional groundwater level rose significantly compared with that in February. At this time, the groundwater level in approximately $72.2 \%$ of the study area was higher than the ecological water level. The entire area was $0.38 \mathrm{~m}$ higher than the ecological water level on average and $0.79 \mathrm{~m}$ higher than the 
ecological water level at the maximum, and these locations were mainly distributed in the middle and southern parts of the study area. At the same time, approximately $11.3 \%$ of the land area in the northern part of the study area was below the ecological water level, which was $0.43 \mathrm{~m}$ below the ecological water level on average. Over time, the area above the ecological water level in the study area gradually increased until it reached the highest state of the regional groundwater level in June and July. Then, approximately $83.5 \%$ of the area exceeded the ecological water level in July, which was $0.98 \mathrm{~m}$ above the ecological water level on average. The highest point was $1.28 \mathrm{~m}$ above the ecological water level. At this time, level 1 accounted for approximately $40.2 \%$ of the total area, which was $1.12 \mathrm{~m}$ above the ecological water level on average. The groundwater level rose most obviously along the Amudarya River and in the southern region, with the highest water level being only $0.5 \mathrm{~m}$ below the ground. The regional groundwater began declining in September. The level 1 area decreased to zero, but the overall $73.2 \%$ was still higher than the ecological water level, which was $0.54 \mathrm{~m}$ higher than the ecological water level on average. The regional groundwater level reached the most reasonable level by the end of the irrigation period in November. Approximately $87.9 \%$ of the regional groundwater level was within the ecological water level, and the average water level was approximately $2.2 \mathrm{~m}$. Subsequently, the regional groundwater level gradually decreased in the northeast and south and reached the lowest value in January. Approximately $75.5 \%$ of the regional groundwater level was lower than the ecological water level, with an average that was $0.55 \mathrm{~m}$ lower than the ecological water level, $29.2 \%$ of the areas were severely low, and the lowest point was approximately 
$1.4 \mathrm{~m}$ below the ecological water level; these sites were mainly distributed in the northeastern and southern parts of the study area. Under the scenario of increased groundwater volatility, the increasing trend of groundwater in the entire region will cause the regional groundwater level to exceed the ecological water level in a larger area, for a longer time, and more often, threatening the sustainable development of the regional ecological environment.

\section{Discussion}

The spatial and temporal distributions of groundwater resources in the lower reaches of the Amudarya River showed strong heterogeneity. Whether on an annual or a monthly scale, the water level changes at different observation points in different geographical locations within the irrigation area were different or even opposite. The monthly changes were more consistent with the progress of irrigation activities. For the entire region, the annual change showed a slight upwards trend. It was worth noting that the volatility of the groundwater level had an obvious trend of increasing each year under such a changing trend. The reason for this was mostly attributed to the influence of human activities. However, according to the results of ecological water level analysis, the implementation of human irrigation activities has not had a positive impact on the regional ecology.

High temporal and spatial heterogeneity is a common characteristic of groundwater changes in irrigation areas (Guo et al., 2021), but in terms of the changing trends of groundwater, the changing trends of irrigation areas in the lower reaches of the Amudarya River were not universal. In the past few decades, many studies have shown 
that global groundwater is falling sharply (Falkenmark, 1997; Wada, 2016), and many irrigation areas located in arid areas have drastically reduced groundwater levels due to excessive groundwater extraction(Xia et al., 2019). Obviously, our research area is a typical counterexample. Since almost all of the regional irrigation water comes from the Amudarya River, the exploitation of groundwater is rare, and backwards water resource management methods (Djumaboev et al., 2019; Karthe et al., 2015) have caused it to be different from the global trend. This provides a good example that tells us that although the exploitation of groundwater has caused many irrigation areas to face many ecological problems, groundwater should be exploited appropriately.

The expansion of arable land and the increase in output value result in an increase in water consumption ( $\mathrm{Li}$ et al., 2019). Similar to this paper, many studies on irrigation areas in arid areas have shown the large impact of human activities on groundwater in irrigation areas (Li et al., 2020; Pan et al., 2020). In our attribution analysis, with the rise of the groundwater level, it is particularly worth noting that as a cause of rising groundwater, the change in the flow of the Amudarya River was not closely related to groundwater. The reason may be that the water diversion and irrigation system of the irrigation area was not based on the amount of the Amudarya River (Wang et al., 2021). This uncertain water diversion system has greatly damaged the ecological environment around the Aral Sea. Additionally, it is not difficult to see from the trend analysis that at each observation point, the temporal and spatial heterogeneity and irregularity of the groundwater level on the annual scale may be due to changes in the regional agricultural planting structure or lack of integrity or regularity in irrigation activities. The monthly 
changes were due to the high consistency of the annual irrigation activities on the time scale. Regional irrigation activities began in March, and this was also the time when the groundwater changed most drastically until the summer irrigation activities reached the highest peak. The groundwater level also reached its highest value. With the decrease in irrigation activities, the groundwater level gradually decreased and reached its lowest value in winter. Furthermore, differences in planting structures and irrigation systems have led to the occurrence of spatial heterogeneity of regional groundwater levels, and the increase in groundwater volatility in recent years may have been caused by the increasing degree of interference of human activities on regional groundwater. All these results indicate that a more specific water resource management system is needed to solve the local ecological and environmental problems.

Under the scenario of increasing groundwater level volatility, the continuously rising groundwater level requires us to consider whether this state will cause more harm to the area in the future. Therefore, we proposed the concept of the ecological water level. At present, there are many studies on the ecological water level of cotton and wheat in other irrigation areas, which are basically similar to our research results (Ibrakhimov et al., 2007; Pengnian et al., 2014; Yiqiang et al., 2019). Based on the concept of ecological water level, we found that the groundwater in most research areas was already higher than the ecological water level at the beginning of the irrigation period. This phenomenon did not improve until November. Combining the results of trend analysis, we predicted that the time in which the groundwater resources in the study area are higher than the ecological water level will increase. Under the 
characteristics of low precipitation and high evapotranspiration in arid areas, the degree of soil salinization in the irrigation area will increase (Qianqian et al., 2011), which will affect the normal growth of crops and cause the degradation of agricultural land (Nachshon, 2018) that directly threatens the normal production and life of human beings. The current research results in this area are very limited, and the duration is relatively long, but it is known that the current phenomenon of the groundwater level rising higher than the ecological water level during the current irrigation period is the problem of regional water resource management. These problems have also led to the ecological crisis of the Aral Sea. Therefore, effective regional water resource management measures are essential. Based on the existing literature, to prevent the continuous rise of the regional groundwater level, the most direct method should be to extract the groundwater in the corresponding areas beyond the ecological water level after the start of the irrigation period. The proportion of water intake and irrigation in these areas should be maintained at 0.5-0.7 (Yang and Ling, 2015). Because the shallow groundwater in the area has a high salt content, the mined groundwater should enter the salt washing plant through the alkali drainage canal to prevent the return of water with high salinity from harming the soil. At the same time, we will vigorously develop drip irrigation to reduce the amount of irrigation water for crops to reduce the amount of infiltration water and improve the efficiency of water resource utilization. For nonirrigation periods, the corresponding area should be "winter irrigation" (Tao et al., 2016)or the amount of water should be increased to ensure that the water level is within a reasonable ecological water level. 
As mentioned above, different from the global changing trend of groundwater and the trend in other irrigation areas, under the influence of unreasonable irrigation systems, the groundwater in the lower Amudarya irrigation area is a typical irrigation area where the groundwater level is increasing each year. Under the influence of such a changing trend, the ecological problems in the region may continue to increase in the future. Based on the ecological water level, this paper proposed regional groundwater management goals, quantified the problems in the spatiotemporal evolution of regional groundwater for the first time, and proposed a groundwater management plan, laying the foundation for deeper regional research. This article aimed to quantify the problems faced by this typical irrigation area. Future research will focus more on the groundwater problem in this area, aiming to provide a quantitative plan of multi-scenario water resource management, introduce groundwater models, and use the results of this article as a modelling target and basis to further improve the regional groundwater management plan. This information will help promote ecological restoration in the Aral Sea region.

\section{Conclusions}

Since 1960, the lower reaches of the Amudarya River have attracted a large number of immigrants to reclaim land for agricultural production, a large amount of river water has been introduced into the irrigation area, unreasonable water resource management methods have caused the Amudarya River to dry up, the groundwater level in the irrigation area has risen, and the regional salinization problem has been serious. Therefore, based on the M-K trend test, wavelet period analysis method, coefficient of 
variation method, and inverse distance weighting method, this paper described the temporal and spatial distribution characteristics of groundwater in the lower Amudarya River irrigation area from 1999 to 2020 and quantified the impact of climate change and human activities on regional groundwater. The maximum height of capillary rise (capillary method) was used to establish ecological water level standards, diagnose and quantify the spatial and temporal distributions of regional groundwater resources, and set up a water level target for sustainable groundwater management in the region, which provided a theoretical basis for regional groundwater management and follow-up work. Combined with the discussion section of this article, the following main conclusions were obtained:

1. From 1990 to 2020, the spatial and temporal distribution characteristics of groundwater in the irrigation area showed strong temporal and spatial heterogeneity, and the groundwater level generally showed a slow rising state under the scenario of increasing volatility. On the annual scale, the water level at each point in the irrigation area had no significant periodicity, and the water level change rate range was between $-0.054 \mathrm{~m} / \mathrm{a}$ and $0.098 \mathrm{~m} / \mathrm{a}$. Additionally, the overall groundwater level in the region has been rising since the sudden change in 2002 . The average uplift rate was $0.015 \mathrm{~m} / \mathrm{a}$. On a monthly scale, the average groundwater level of each month except November showed an increasing trend, and the rate of increase was the fastest in March (0.029 $\mathrm{m} / \mathrm{a})$. Additionally, the groundwater growth rate, average groundwater level, and fluctuation range of groundwater level during the irrigation period (March to October) were higher than those in the non-irrigation period (January, February, November, and 
December) by $0.007 \mathrm{~m} / \mathrm{a}, 0.64 \mathrm{~m}$, and $0.2 \mathrm{~m}$, respectively.

2. Human activities were the main factors affecting the regional annual groundwater level changes and the annual groundwater level fluctuations, accounting for $67.6 \%$ and $78.9 \%$ of all influencing factors, while natural factors accounted for only $32.4 \%$ and $21.1 \%$. Among them, the average groundwater level had a strong correlation with the arable land area, agricultural output and population, and the correlation coefficients were $0.89,0.88$, and 0.84 , respectively. The correlation between the CV value of groundwater and these three factors was $0.56,0.67$, and 0.68 , respectively. In terms of natural factors, the average water level and groundwater CV values had a low correlation with various natural factors. The correlation between precipitation and average groundwater level and groundwater $\mathrm{CV}$ value was the highest among natural factors, but the values were only 0.49 and 0.21 .

3. The water level for the sustainable use of regional groundwater (ecological water level) should be at $1.78 \mathrm{~m}-2.78 \mathrm{~m}$. Starting in March each year, approximately $72.2 \%$ of the area in the central and southern parts of the irrigation area has been 0.38 $\mathrm{m}$ above the ecological water level. It reached its highest state in July, and approximately $83.5 \%$ of the area exceeded the ecological water level, which was 0.98 $\mathrm{m}$ above the ecological water level on average. The highest water level was only $0.5 \mathrm{~m}$ below the ground. The regional groundwater level began to decline in September and reached its lowest value in January. Approximately $75.5 \%$ of the groundwater levels in the north-eastern and southern regions were lower than the ecological water level, which was $0.55 \mathrm{~m}$ lower than the ecological water level on average. Excessively high 
water levels increase the risk of regional salinization. We believe that under future regional groundwater development (water level rise, extreme water level changes), the regional ecological environment will worsen. Therefore, it is necessary to use the ecological water level of this study to set groundwater targets and to use drip irrigation to improve water resource utilization efficiency, reduce regional groundwater levels, and maintain the sustainable development of regional groundwater in future regional water resource management.

\section{Ethical Approval and Consent to Participate:}

This article does not contain any studies with human participants or animals performed by any of the authors.

\section{Consent to Publish:}

All authors have consented to publish this manuscript.

\section{Authors Contributions:}

All authors contributed to the study conception and design. Material preparation, data collection and analysis were performed by Guo CY, Liu T, Hunag Y, Li ZY, Wang Z, Zan CJ, Akmalov S, Duan YC and Guo F. The first draft of the manuscript was written by Guo CY and all authors commented on previous versions of the manuscript. All authors read and approved the final manuscript.

\section{Acknowledgements:}

This study was supported by the Strategic Priority Research Program of Chinese Academy of Sciences (Grant No. XDA20060303), International Partnership Program of the Chinese Academy of Sciences (Grant No. 131551KYS B20160002), CAS Inter- 
displinary Innovation Team (Grant No. JCTD-2019-20), Regional Collaborative Innovation Project of Xinjiang Uygur Autonomous Regions (Grant No. 2020E01010), K.C.Wong Education Foundation (GJTD-2020-14); Talent Start Project (Grant No.550221020); Innovation and Entrepreneurship Doctoral program (Grant No.JSSCBS20210862).

\section{Fundings:}

Strategic Priority Research Program of the Chinese Academy of Sciences, PanThird Pole Environment Study for a Green Silk Road (Grant No. XDA20060303);

The International Partnership Program of the Chinese Academy of Sciences (Grant No. 131551KYS B20160002);

CAS Inter- displinary Innovation Team (Grant No. JCTD-2019-20);

Regional Collaborative Innovation Project of Xinjiang Uygur Autonomous Regions (Grant No. 2020E01010);

K.C.Wong Education Foundation (GJTD-2020-14);

Talent Start Project (Grant No.550221020);

Innovation and Entrepreneurship Doctoral program (Grant No.JSSCBS20210862).

\section{Competing Interests:}

The authors have no competing interests to declare that are relevant to the content of this article.

\section{Availability of data and materials}

Data used in the research work have been acknowledged, and data and code are available on request. 


\section{References}

Alashan, S., 2020. Combination of modified Mann-Kendall method and Sen innovative trend analysis. ENGINEERING REPORTS 2. https://doi.org/10.1002/eng2.12131

Buchanan, S., Triantafilis, J., 2009. Mapping Water Table Depth Using Geophysical and Environmental Variables. GROUND WATER 47, 80-96. https://doi.org/10.1111/j.1745-6584.2008.00490.x

Cai, X.M., McKinney, D.C., Rosegrant, M.W., 2003. Sustainability analysis for irrigation water management in the Aral Sea region. AGRICULTURAL SYSTEMS 76, 1043-1066. https://doi.org/10.1016/S0308-521X(02)00028-8

Chanjuan, Z., Yue, H., Junli, L., Tie, L., Anming, B., Wei, X., Zhibin, L., 2021. Analysis of water balance in Aral Sea and the influencing factors from 1990 to 2019. Hupo Kexue 33, 1265-1275. https://doi.org/10.18307/2021.0426

Cretaux, J.F., Kouraev, A. v, Papa, F., Berge-Nguyen, M., Cazenave, A., Aladin, N., Plotnikov, I.S., 2005. Evolution of sea level of the big Aral Sea from satellite altimetry and its implications for water balance. JOURNAL OF GREAT LAKES RESEARCH 31, 520-534. https://doi.org/10.1016/S0380-1330(05)70281-1

Davis, M., 2012. Food and Agriculture Organization of the United Nations, CHEMICALS, ENVIRONMENT, HEALTH: A GLOBAL MANAGEMENT PERSPECTIVE.

Djumaboev, K., Yuldashev, T., Holmatov, B., Gafurov, Z., 2019. Assessing Water Use, Energy Use And Carbon Emissions In Lift- Irrigated Areas: A Case Study From 
Karshi Steppe In Uzbekistan. IRRIGATION AND DRAINAGE 68, 409-419. https://doi.org/10.1002/ird.2321

Doell, P., 2009. Vulnerability to the impact of climate change on renewable groundwater resources: a global-scale assessment. ENVIRONMENTAL RESEARCH LETTERS 4. https://doi.org/10.1088/1748-9326/4/3/035006

Falkenmark, M., 1997. Meeting water requirements of an expanding world population. PHILOSOPHICAL TRANSACTIONS OF THE ROYAL SOCIETY OF LONDON SERIES B-BIOLOGICAL SCIENCES 352, 929-936. https://doi.org/10.1098/rstb.1997.0072

Famiglietti, J.S., 2014. The global groundwater crisis. NATURE CLIMATE CHANGE 4, 945-948. https://doi.org/10.1038/nclimate2425

Giordano, M., 2009. Global Groundwater? Issues and Solutions. ANNUAL REVIEW OF ENVIRONMENT AND RESOURCES 34, 153-178. https://doi.org/10.1146/annurev.environ.030308.100251

Giordano, R., Liersch, S., Vurro, M., Hirsch, D., 2010. Integrating local and technical knowledge to support soil salinity monitoring in the Amudarya river basin. JOURNAL OF ENVIRONMENTAL MANAGEMENT 91， 1718-1729. https://doi.org/10.1016/j.jenvman.2010.03.010

Guo, C., Liu, T., Niu, Y., Liu, Z., Pan, X., de Maeyer, P., 2021. Quantitative analysis of the driving factors for groundwater resource changes in arid irrigated areas. HYDROLOGICAL PROCESSES 35. https://doi.org/10.1002/hyp.13967

Honglang, X., Guodong, C., Caizhi, L., Juan, R., Sai, W., 2008. Eco-hydrological 
Observational Experiments of the Heihe River Basin and Integrated Eco-water Management Research at Watershed Scale. Advance in Earth Sciences 23, 666670.

Ibragimov, N., Evett, S.R., Esanbekov, Y., Kamilov, B.S., Mirzaev, L., Lamers, J.P.A., 2007. Water use efficiency of irrigated cotton in Uzbekistan under drip and furrow irrigation. AGRICULTURAL WATER MANAGEMENT 90, 112-120. https://doi.org/10.1016/j.agwat.2007.01.016

Ibrakhimov, Khamzina, Forkutsa, 2007. Groundwater table and salinity: Spatial and temporal distribution and influence on soil salinization in Khorezm region. Irrigation and Drainage Systems 21, 219-236.

Izhitskiy, A.S., Zavialov, P.O., Sapozhnikov, P. v, Kirillin, G.B., Grossart, H.P., Kalinina, O.Y., Zalota, A.K., Goncharenko, I. v, Kurbaniyazov, A.K., 2016. Present state of the Aral Sea: diverging physical and biological characteristics of the residual basins. SCIENTIFIC REPORTS 6. https://doi.org/10.1038/srep23906

Jiang, L., Guli-Jiapaer, Bao, A., Yuan, Y., Zheng, G., Guo, H., Yu, T., de Maeyer, P., 2020. The effects of water stress on croplands in the Aral Sea basin. JOURNAL $\begin{array}{llll}\text { OF } & \text { CLEANER }\end{array}$ https://doi.org/10.1016/j.jclepro.2020.120114

Jiaqi, Z., Yiyang, D., Shenglin, Q., Yong, Z., Kuan, L., Yongnan, Z., 2021. Advances in Ecological Groundwater Level Threshold in Arid Oasis Regions. Journal of China Hydrology.

Karthe, D., Chalov, S., Borchardt, D., 2015. Water resources and their management in 
central Asia in the early twenty first century: status, challenges and future prospects. ENVIRONMENTAL EARTH SCIENCES 73, 487-499. https://doi.org/10.1007/s12665-014-3789-1

Kewei, W., Lihua, G., Feng, J., 2021. A Method of Seabed DEM Modeling Based on the Improved Inverse Distance Weighted Interpolation Algorithm. Hydrographic Surveying and Charting.

Kopec, D., Michalska-Hejduk, D., Krogulec, E., 2013. The relationship between vegetation and groundwater levels as an indicator of spontaneous wetland restoration. ECOLOGICAL ENGINEERING 57, 242-251. https://doi.org/10.1016/j.ecoleng.2013.04.028

LANDE, R., 1977. COMPARING COEFFICIENTS OF VARIATION. SYSTEMATIC ZOOLOGY 26, 214-217. https://doi.org/10.2307/2412845

Li, H.H., Lu, Y.D., Zheng, C., Zhang, X.N., Zhou, B., Wu, J., 2020. Seasonal and InterAnnual Variability of Groundwater and Their Responses to Climate Change and Human Activities in Arid and Desert Areas: A Case Study in Yaoba Oasis, Northwest China. WATER 12. https://doi.org/10.3390/w12010303

Li, M., Sun, H., Singh, V.P., Zhou, Y., Ma, M.W., 2019. Agricultural Water Resources Management Using Maximum Entropy and Entropy-Weight-Based TOPSIS Methods. ENTROPY 21. https://doi.org/10.3390/e21040364

Liu, Z., Huang, Y., Liu, T., Li, J., Xing, W., Akmalov, S., Peng, J., Pan, X., Guo, C., Duan, Y., 2020. Water Balance Analysis Based on a Quantitative Evapotranspiration Inversion in the Nukus Irrigation Area, Lower Amu River 
Basin. REMOTE SENSING 12. https://doi.org/10.3390/rs12142317

Mi, L., Xiao, H., Zhang, J., Yin, Z., Shen, Y., 2016. Evolution of the groundwater system under the impacts of human activities in middle reaches of Heihe River Basin (Northwest China) from 1985 to 2013. HYDROGEOLOGY JOURNAL 24, 971-986. https://doi.org/10.1007/s10040-015-1346-y

Micklin, P., 2007. The Aral Sea disaster, in: ANNUAL REVIEW OF EARTH AND $\begin{array}{lll}\text { PLANETARY SCIENCES. } & \text { 47-72. }\end{array}$ https://doi.org/10.1146/annurev.earth.35.031306.140120

MICKLIN, P.P., 1988. DESICCATION OF THE ARAL SEA - A WATER MANAGEMENT DISASTER IN THE SOVIET-UNION. SCIENCE 241, 1170 1175. https://doi.org/10.1126/science.241.4870.1170

Mingan, S., 2006. Soil physics. Beijing Higher Education Press, Beijing.

Nachshon, U., 2018. Cropland Soil Salinization and Associated Hydrology: Trends, Processes and Examples. WATER 10. https://doi.org/10.3390/w10081030

Nezlin, N.P., Kostianoy, A.G., Lebedev, S.A., 2004. Interannual variations of the discharge of Amu Darya and Syr Darya estimated from global atmospheric precipitation. JOURNAL OF MARINE SYSTEMS 47, 67-75. https://doi.org/10.1016/j.jmarsys.2003.12.009

Pan, X., Wang, W., Liu, T., Huang, Y., de Maeyer, P., Guo, C., Ling, Y., Akmalov, S., 2020. Quantitative Detection and Attribution of Groundwater Level Variations in the Amu Darya Delta. WATER 12. https://doi.org/10.3390/w12102869

Pearson, K., 1901. Mathematical contributions to the theory of evolution. X. 
Supplement to a memoir on skew variation. PHILOSOPHICAL TRANSACTIONS OF THE ROYAL SOCIETY OF LONDON SERIES ACONTAINING PAPERS OF A MATHEMATICAL OR PHYSICAL CHARACTER 197, 443-459. https://doi.org/10.1098/rsta.1901.0023

Pengnian, Y., Bin, W., Shuixian, W., Xinguang, D., Lei, L., 2014. Research on irrigation schedule of cotton drip irrigation under plastic film based on the different ground water table in arid areas. Agricultural Research in the Arid Areas.

Qianqian, G., Zhiwen, H., Guohua, W., 2011. NoResearch Progress on Soil Salinization in Arid Irrigated Area of Northwestern China Title. Chinese Agricultural Science Bulletin 27, 246-250.

Ruji, H., Xi, C., Fengqing, J., Yajun, W., Abuduwaili, J., Abulekem, A., 2011. Threat of Human Activities to Hydrological Regime in Central Asia. Arid Zone Research.

Shuixian, W., Bin, W., Pengnian, Y., Xia, L., Xinguang, D., 2011. Determination of the Ecological Groundwater Depth Considering Ecological Integrity over Oasis Irrigation Areas in the Yanqi Basin. Resources Science.

Siebert, S., Burke, J., Faures, J.M., Frenken, K., Hoogeveen, J., Doell, P., Portmann, F.T., 2010. Groundwater use for irrigation - a global inventory. HYDROLOGY AND EARTH SYSTEM SCIENCES $14, \quad 1863-1880$. https://doi.org/10.5194/hess-14-1863-2010

Song, Y., Guo, Z., Lu, Y., Yan, D., Liao, Z., Liu, H., Cui, Y., 2017. Pixel-Level Spatiotemporal Analyses of Vegetation Fractional Coverage Variation and Its Influential Factors in a Desert Steppe: A Case Study in Inner Mongolia, China. 
WATER 9. https://doi.org/10.3390/w9070478

Stein, M.L., 2009. SPATIAL INTERPOLATION OF HIGH-FREQUENCY MONITORING DATA. ANNALS OF APPLIED STATISTICS 3, 272-291. https://doi.org/10.1214/08-AOAS208

Tao, L., Guangsheng, Z., Kaiyan, T., Li, Z., 2016. Review on research of irrigation regime and its environmental effect in winter wheat field of North China Plain. Acta Ecologica Sinica 36, 5979-5986.

Varouchakis, E.A., Hristopulos, D.T., 2013. Comparison of stochastic and deterministic methods for mapping groundwater level spatial variability in sparsely monitored basins. ENVIRONMENTAL MONITORING AND ASSESSMENT 185, 1-19. https://doi.org/10.1007/s10661-012-2527-y

Wada, Y., 2016. Modeling Groundwater Depletion at Regional and Global Scales: Present State and Future Prospects. SURVEYS IN GEOPHYSICS 37, 419-451. https://doi.org/10.1007/s10712-015-9347-x

Wang, M., Chen, X., Sidike, A., Cao, L., DeMaeyer, P., Kurban, A., 2021. Optimal Allocation of Surface Water Resources at the Provincial Level in the Uzbekistan Region of the Amudarya River Basin. WATER 13. https://doi.org/10.3390/w13111446

Wang, S.P., Zhang, Q., Yue, P., Wang, J.S., 2020. Effects of evapotranspiration and precipitation on dryness/wetness changes in China. THEORETICAL AND APPLIED CLIMATOLOGY 142, 1027-1038. https://doi.org/10.1007/s00704020-03336-8 
Wang, Y., Chen, M., Yan, L., Yang, G., Ma, J., Deng, W., 2020. Quantifying Threshold Water Tables for Ecological Restoration in Arid Northwestern China. GROUNDWATER 58, 132-142. https://doi.org/10.1111/gwat.12934

Xia, J., Wu, X., Zhan, C., Qiao, Y., Hong, S., Yang, P., Zou, L., 2019. Evaluating the Dynamics of Groundwater Depletion for an Arid Land in the Tarim Basin, China. WATER 11. https://doi.org/10.3390/w11020186

Yang, L., Ling, S., 2015. Rational allocation of surface water and groundwater in irrigated area based on support vector machine. Water Saving Irrigation 5, 50-53. Yiqiang, Z., Qiaoyan, B., Huiyong, W., 2019. Discussion on suitable depth of groundwater level, water-saving threshold and water-salt balance in Hetao irrigation district. Journal of Irrigation and Drainage 38, 83-86. 